\title{
Combining ecohydrologic and transition probability-based modeling to simulate vegetation dynamics in a semi-arid rangeland
}

\begin{abstract}
Drylands support pastoralist social-ecological systems around the world. Ecological function in these water-limited environments frequently depends on tightly coupled, nonlinear interactions between water, soil, vegetation, and herbivores. Numerous complexity-based approaches have modeled localized ecohydrological feedbacks to yield insights into dryland landscape organization and emergent dynamics. The relevance of these models to management and sustainability continues to increase as researchers incorporate ecological processes at multiple scales and social-ecological variables like herding practices. However, many processes vary in their importance depending on ecological context, so there is a continuing need to construct models tailored to different contexts. We developed a model for semi-arid rangelands that experience highly variable rainfall, substantial Hortonian runoff during rain events, patchy vegetation structure, and grazing-influenced patch transitions. The model couples an existing, mechanistic cellular automata model of hillslope water balance with a dynamic vegetation model in which probabilistic transitions between bare, annual grass, perennial grass patches depend on soil moisture and grazing intensity. The model was parameterized based on a field site in Kenya, from which we had empirical hydrological measurements and several years of patch-to-hillslope scale measurements of vegetation structure. The model domain is a 100x100 grid of $2 \times 2 \mathrm{~m}$ cells,
\end{abstract}

(C) 2016. This manuscript version is made available under the Elsevier user license http://www.elsevier.com/open-access/userlicense/1.0/ 
it simulates seasonal cycles of growing seasons followed by dry seasons, and it computes daily soil moisture based on stochastic rainfall forcings. Patch type transitions can occur twice during each seasonal cycle: at the end of the growing season, with probabilities based on average growing-season soil moisture availability; and at the end of the dry season, with probabilities based on grazing intensity and antecedent growing-season soil moisture. By parameterizing grazing intensity as a per-patch impact, it can be interpreted as the degree of forage depletion at which a herder decides to leave the area. We conducted a series of simulation experiments, principally altering runoff channelization and grazing intensity. The model generated plausible vegetation dynamics across the range of grazing intensities simulated. Vegetation cover fluctuated seasonally, but never collapsed completely, even at the highest grazing intensity. At low to intermediate grazing, we observed multi-decadal switches in fractional perennial cover, triggered by periods of below- or above- average rainfall. At low to intermediate grazing intensities, we noted emergent spatial patterning in the form of a step-like increase in vegetation density in the lower half of the domain. With a vegetation patch transitions governed by mechanistic water balance dynamics as well as grazing intensities that represent herder decisionmaking, the model holds great potential for further explorations of how land use, climate, and spatial heterogeneity affect the functioning of a dryland pastoralist social-ecological system.

\section{Keywords}

Cellular automata, ecohydrology, grazing, runoff, semi-arid, transition 


\section{Introduction}

Arid and semi-arid lands cover $41 \%$ of the Earth's land surface (Reynolds et al., 2007), and over $70 \%$ of global drylands occur in developing countries (Millennium Ecosystem Assessment, 2005). Drylands are characterized not only by low annual precipitation relative to potential evapotranspiration, but also by high spatiotemporal variability in rainfall. These conditions often make drylands marginal or unsuitable for rainfed agriculture, but they can support extensive livestock production with mobile herds that track forage availability as it fluctuates through space and time. Globally, drylands support hundreds of millions of pastoralists, who derive all or most of their livelihood from livestock husbandry (Reynolds et al., 2007). While a range of adaptations have historically allowed pastoralist societies to cope with harsh and variable environmental conditions, today many are facing ongoing pressures of loss of land rights, limited mobility, land degradation, and climate change - trends whose combined effects are undermining the resilience of both livelihoods and landscapes in pastoralist social-ecological systems (Catley et al., 2013). Understanding the interactions between land use, climate change, and landscape structure and function are central to studying and promoting sustainability in drylands.

The organization and functioning of dryland ecosystems tends to be governed by tightly coupled interactions and feedbacks between water, soil, and vegetation. Dryland vegetation is typically spatially heterogeneous, with patches of individual plants or vegetation separated by bare or sparse interpatch areas (Deblauwe et al., 2008). This structural heterogeneity becomes selfreinforcing through its effects on soil moisture distribution and resulting vegetation responses. 
Rainfall events in drylands tend to be infrequent and intense, often exceeding the rate of infiltration and generating Hortonian surface flows except where soils are very sandy (Wilcox and Newman, 2005; Saco et al., 2006). Vegetation patches act to slow or obstruct surface flows, leading to higher infiltration in patches (Ludwig et al., 2005). Also, vegetated patches tend to feed back positively on soil moisture during the growing season by reducing evaporation following rainfall (Franz et al., 2012). Greater soil moisture availability facilitates greater plant growth, and increased soil permeability from root growth and associated biotic activity (Rietkerk et al., 2002). Greater flow obstruction and soil permeability results in enhanced local water infiltration in subsequent rainfall events. In the bare interpatch areas, on the other hand, limited infiltration and greater evaporative exposure result in lower soil moisture, which in turn limits subsequent vegetation growth and infiltration (Breshears et al., 2009).

The two sets of positive feedbacks occurring respectively in vegetated and bare patches, and lateral resource redistribution between them, can generate the hallmark self-organized patchy structure of dryland vegetation (King et al., 2012). These so-called scale-dependent feedbacks can also generate emergent temporal dynamics of nonlinear changes and threshold behaviors in response to incremental changes in environmental conditions such as mean annual precipitation (Rietkerk and van de Koppel, 1997; Turnbull et al., 2012). Using Turing-like activationinhibition equations, several modeling studies have identified threshold levels of precipitation that result in two possible alternative stable states (bare or vegetated) and a single, selfreinforcing bare state (Rietkerk and Van de Koppel, 2008; Kéfi et al., 2010). The domination of self-reinforcing bare conditions thus offers a process-based definition of dryland degradation or desertification (Reynolds et al., 2007). 
Grazing can affect patch-based water-soil-vegetation feedbacks, and thereby cause nonlinear changes in emergent landscape function. Heavy grazing can weaken the resource-conserving feedbacks in vegetation patches: by reducing vegetation cover, the landscape after a dry season is less able to intercept runoff in the next rainfall event, reduce evaporation, or convert soil moisture into plant productivity (van de Koppel et al., 2002; Rietkerk et al., 2004). Modeling studies (Rietkerk et al., 1996; Kefi et al., 2007) as well as empirical research (Rietkerk et al., 2000) have shown nonlinear and threshold changes in vegetation structure and productivity in response to increasing grazing intensity. Dryland grazing systems have become a flagship ecosystem for studying emergent nonlinearities and catastrophic regime shifts to degraded states (Scheffer et al., 2001); and continue to provide a fertile context for developing modeling approaches that link localized ecological interactions and emergent system behaviors.

A key challenge is to build models that integrate these complexities appropriately for a given environmental and land use context. To meet this challenge, many scholars approach dryland grazing systems from the perspective of complex adaptive systems, using spatially explicit cellular automata (CA) and agent-based models (ABMs) to understand the dynamics and behaviors that emerge from localized interactions and processes. Such models use rules based on conditions experienced by individual entities to determine the decisions, dynamics and/or state transitions for each entity in a system. When CA models are used to track the dynamics of individual cells in a spatial matrix, they provide advantageous tools for understanding and projecting the response of dryland systems to climate and land use drivers. As system-wide properties emerge from local dynamics, subsequent localized dynamics can respond to system- 
wide changes, creating a coupling of processes across scales (Wiegand et al., 2003). Another advantage of such models arises because many emergent landscape- or ecosystem-level behaviors are difficult or impossible to study empirically because of the necessary spatial or temporal extent of the study, and inability to manipulate, replicate, or control the variables of interest (Perry and Enright, 2006). In simulation models, those system-level behaviors emerge based on smaller scale processes, for which there is often more useful data and causal relations among variables are better understood (Grimm et al., 2005).

Several research programs have capitalized on the flexibility of grid-based simulation approaches, tailoring models to specific ecological contexts and research questions by incorporating different processes and varying degrees of mechanistic reality for those processes, in order to strike a balance between parsimony, complexity, and ecological relevance (Tietjen and Jeltsch, 2007). For example, a family of patch-based simulation models was developed to simulate effects of grazing intensity and rainfall variability on shrub-grass dynamics in the sandy soils of the southern Kalahari in Africa (Jeltsch et al., 1996, 1997a , 1997b, 1998; Weber et al., 2000). In order to simulate the emergent outcomes of woody-herbaceous plant competition under different environmental conditions, the models: aggregated yearly rainfall to assign classes of soil moisture availability in two soil layers; simulated grass-shrub competition for water; incorporated different additional processes such as grazing, fire, and disturbance; and applied rules for transitions of herbaceous and woody vegetated grid cells. Another dryland model, EcoHy D, incorporated a hydrological submodel with greater mechanistic detail, including different wetting front and macropore infiltration rates, and unidirectional surface runoff (Tietjen et al., 2009), and coupled it with a detailed demographic submodel of herbaceous and woody 
vegetation dynamics, which also sought to investigate woody cover change (shrub encroachment) in response to changing rainfall patterns, $\mathrm{CO}_{2}$ levels, and grazing (Tietjen et al., 2010; Lohmann et al., 2012). The grid-based Mediterranean vegetation models developed by Koniak \& Noy-Meir (2009) and Bar Massada et al. (2009), on the other hand, do not explicitly include ecohydrological dynamics, but instead utilize continuous probability functions to describe how different ecological processes (succession, grazing, fire, land clearing) and plant demographic rates (reproduction, dispersal, colonization, mortality, etc.) interact to affect transition rates between different plant functional types.

The goal of our research was to develop a new grid-based model tailored to the specific context of drylands that have: (1) patchy vegetation, (2) relatively low infiltration rates, (3) complex twodimensional runoff patterns, and (4) limited availability of data regarding fine-scale or mechanistic plant demographic responses to stressors. These conditions characterize our study area in north-central Kenya as well as many African, Australian, Mediterranean, and Southwestern U.S. drylands. The first three conditions relate to ecohydrology, and are known to exert strong, nonlinear influences on the productivity and self-organization of dryland ecosystems (Ludwig et al., 2005; Turnbull et al., 2008). To account for these important effects, Franz et al (2012) developed a rule-based hillslope water balance model and numerical scheme to couple surface and subsurface flow processes; its inclusion in a simulation model of herbivore and vegetation dynamics will therefore improve our understanding of these systems' emergent behavior under changing environmental stressors at ecologically relevant spatial and temporal scales. The fourth condition, a paucity of detailed data or mechanistic understanding of environmental effects on vegetation dynamics, may exist in a number of situations where only 
expert knowledge or coarser-scale vegetation monitoring data is available. The scales and phenomenological nature of field monitoring data, remote sensing data, local observational information, and expert knowledge regarding livestock impacts on vegetation, lend themselves more readily to estimating transition rates than to estimating more mechanistic vegetation dynamic parameters. Thus, we sought to couple a mechanistic hydrological model with a a nonmechanistic, transition probability-based representation of vegetation and grazing dynamics, to generate a new hybrid modeling framework useful for projecting the effects of environmental stressors under a common set of ecohydrological conditions and data limitations found in our study system and other dryland systems around the world.

We constructed a grid-based model of hillslope herbaceous vegetation dynamics to include detailed, mechanistic processes that were previously found to be influential in in this area; as well as non-mechanistic processes for which we have some phenomenological understanding of their higher-level, emergent patterns and behaviors. This approach is advocated as a strategy in pattern-oriented ABM modeling, as a way to more fully utilize existing information from finescale dynamics as well as higher-order patterns in an iterative process of building useful, application-relevant models (Wiegand et al., 2003; Grimm et al., 2005). Our model builds upon a static hillslope cellular automata model of soil-water dynamics, parameterized with detailed measurements in different patch types in the study system (Franz et al., 2012). We have coupled it with a dynamic, two-stage vegetation transition model governed by rainfall and grazing pressure, to explore their influence on loss, persistence, or recolonization of vegetation patches, from which emerge landscape-scale trends in ecological function and organization. We present 
the model as a grid-based analogue to an ABM, in order to facilitate its coupling with ABMs of grazing behavior, herder decision-making, and other complex dynamics in future work.

The study is motivated by the need to understand the emergent behaviors and trajectories of ecological change that result from different land use practices in the study region, particularly grazing intensity, which has been changing markedly in recent decades. East African drylands tend to be quite resilient to ungulate herbivory when herds are mobile and can move opportunistically over large landscapes (Reid et al., 2014). Because of the extensive, heterogeneous resource base, there is only weak coupling of consumer-resource dynamics in any given area of the herbivores' range (Illius and O'Connor, 1999). However, when mobility is restricted to a given area, herbivore pressure can generate positive feedbacks that can lead to persistent degraded states (Rietkerk and van de Koppel, 1997). The study region in Kenya is utilized by subsistence pastoralists, whose historic mobility and extensive land access have been profoundly curtailed in recent decades. Today, many parts of their network of customary grazing areas are now privately-owned, occupied by other groups, or in conflict zones - all of which make long-distance movements more challenging and/or costly (Letai and Lind, 2013). This has in turn led to more intensive localized grazing pressure, particularly in the dry season when livestock were customarily taken to more distant key resource areas (Letai and Lind, 2013). Residents describe the quality and quantity of local grazing resources as greatly reduced as compared to 30 years ago (King, 2008).

Also, rainfall patterns in the region have shifted toward fewer, heavier rainfall events over the last half a century (Franz et al., 2010). However, most recent climate models project that East 
Africa may become less drought-prone in the future, but those projections still carry substantial uncertainties, and depend on which indices of drought are used, and they are highly sensitive to future greenhouse gas concentrations (Orlowsky and Senviratne, 2013). Developing a simulation model for this landscape will facilitate subsequent research to explore the ecological consequences of changes in rainfall patterns, as well as alternative land management strategies including different grazing patterns and restoration interventions.

\section{Methods}

\subsection{Study Area}

The study area is Koija Group Ranch, in the Mukogodo Group Ranch Division in Laikipia County, in the Ewaso Nyiro River basin of north-central Kenya $\left(00^{\circ} 33.69^{`} \mathrm{~N}, 36^{\circ} 54.09^{`} \mathrm{E}, 1,600\right.$ masl). This area is in equatorial Kenya, and receives 400mm mean annual precipitation (MAP), with high interannual variability $(\mathrm{CV}=40 \%)$. Rainfall is concentrated in two rainy seasons per year, typically occurring from March to May and November to December. An analysis of longterm total precipitation records (i.e. gage data beginning in 1930) from the basin indicated that seasonal rainfall totals have had minimal change but that daily rainfall patterns have shifted to more infrequent and intense events (Franz et al., 2010). An analysis of seasonal rainfall totals from the same records showed no significant autocorrelation between consecutive rainy seasons (unpublished data). 
Koija Group Ranch, one of fifteen Group Ranches in this division, was established by the Government of Kenya in 1971, granting communal ownership to the Laikipia Maasai people who customarily resided in the area. These pastoralists own and tend mixed herds of cattle, goats, sheep, and less commonly camels and donkeys. There are approximately 200 households and 2200 total residents residing in the 7605 ha Group Ranch. Their livestock holdings amount to about 3700 tropical livestock units $(1 \mathrm{TLU}=1$ cattle $=10$ goats/sheep $)$ and residents utilize the grazing resources communally (Kaye-Zwiebel and King, 2014). In a closed grazing system, this would yield a stocking rate of about $2 \mathrm{ha} / \mathrm{TLU}$. However, cattle are customarily taken to grazing areas or loaned to family members outside the Group Ranch, particularly during dry seasons and droughts, resulting in a dynamic stocking density. The area also has several species of wild herbivores, including elephants, plains zebras, Grevy's zebras, buffalo, impala, and gerenuk.

The landscape is gently rolling in most areas, with red lateritic sandy clay loam soils, and has a mosaic of herbaceous vegetation patches, with $50 \%$ bare soil on average, and $5-25 \%$ woody canopy cover dominated by Acacia mellifera, A. etbaica, and A. tortilis (King et al., 2012). The herbaceous layer tends to be patchy at the 1 to $10 \mathrm{~m}$ scale, which are comprised either predominantly of perennial grasses (most commonly in the Cynodon, Digitaria, and Pennisetum genera), or of annual grasses dominated by Eragrostis tenuifolia. Compared to residents' descriptions of the area 20-30 years ago, and compared to adjacent privately owned ranches with moderate to no livestock grazing for the last 30 years, the landscape at Koija today shows strikingly less herbaceous cover and perennial grass abundance and diversity, and more bare soil and evidence of erosion (King, 2008). Trends in woody cover change at the site are not yet fully understood. A 7-year monitoring study using the patch-scale Landscape Function Analysis 
methodology (Tongway and Hindley, 2004) found frequent inter-seasonal transitions between bare, annual, and perennial vegetation patches, while some bare soil patches with sealed surfaces were highly persistent (King, unpublished manuscript). A runoff measurement study found that bare areas have markedly lower infiltration rates than grass patches and tree-grass patches (Franz et al., 2012). Driven by low infiltration and little flow obstruction in in bare areas, a positive feedback exists between the bare patches, surface water convergence (King et al., 2012), erosion channel formation on hillslopes (King, unpublished manuscript), and higher microtopographic elevation of vegetation patches. Complex surface patterns of horizontal rainfall runoff and runon, reflecting the erosion channelization around some vegetation patches, are visible during and immediately following a rain event (Figure 1a).

\section{<FIGURE 1>}

\subsection{Model Description}

We developed a dynamic model, called MVUACHACHE (Modeling Vegetation dynamics Using A CA model with Hydrological dynamics And Coupled Herbivory Effects). It is based on an existing grid-based water balance model that described daily 1-layer soil moisture dynamics in representative patches of bare soil, perennial grass, and tree patches (Figure 1b; Franz et al., 2012). In MVUACHACHE, we add additional patch types to the water balance model, then link that model with a new dynamic vegetation and grazing model. In the following sections we give an overview of the model workflow, summarize key features and updates of the water balance 
submodel, present new model components for vegetation and herbivory dynamics, and explain the construction and calibration of transition probability functions.

The Methods section is structured to provide the clearest flow of ideas for understanding the model's operation. We also present a summary of the model using the updated ODD Protocol (Grimm et al., 2010) in Appendix A to provide a standardized description of the model elements. Additionally, in complex model development, the processes of evaluation, calibration, and verification are often iterative rather than linear, and thus are difficult to describe as ordered stages. Throughout the Methods section, we identify in italics the steps we have taken in terms of data evaluation, implementation verification, model output verification (includes calibration), model analysis (includes sensitivity), and model output corroboration, following the “evaludation" terminology of Angusiak et al. (2014). In Appendix D we provide a summary of the term definitions and how the procedures were implemented.

\subsubsection{Model overview}

The model domain is a 100x100 cell grid of 2x2m cells, representing a hillslope. The top of the domain is a noflow boundary representing the hilltop, and the two sides of the domain are joined periodically forming a wrapped cylindrical domain. The lower boundary represents a stream channel where surface flow can exit freely out of the domain and is considered lost to the system. The model simulates the effects of environmental conditions sequentially - in a 90-day growing season then in a 90-day dry season - during each full seasonal cycle. Soil water relations govern transitions during the growing season, while vegetated patch persistence during the dry season is governed by antecedent growing-season soil moisture and grazing intensity. Figure 2 illustrates 
the framework and workflow of the model for one growing season and one dry season. Figure 3 shows the possible patch transitions that can occur at the end of the growing season and at the end of the dry season.

In the growing season, the model first computes the daily water balance for each of the five patch types - degraded bare soil $(B B)$, bare soil $(B)$, annual grasses $(A)$, perennial grasses $(P)$, and trees with herbaceous understory $(T)$ - driven by daily stochastic rainfall forcings. The patch categories are assumed to represent the following conditions: $B$ and $B B$ patches contain $<10 \%$ cover of annual or perennial grasses; $A$ patches contain $>10 \%$ annual grass cover and $<10 \%$ perennial cover; $P$ patches contain $>10 \%$ perennial grass cover and any amount of annual grass cover; $T$ patches contain tree canopy and $>10 \%$ perennial grass cover; which correspond to categories in field monitoring data used in model calibration (see Appendix B). In unvegetated patches, the model computes the daily soil moisture. In vegetated patches, the model computes the daily water stress value based on the soil moisture value and patch type-specific water use parameters. For convenience, water stress was converted to water stress avoidance (i.e. 1 minus water stress), so that the value increases with higher soil water availability, as it does for soil moisture in unvegetated patches. At the end of the growing season water balance simulations, the average daily soil moisture is calculated for unvegetated patches, and average daily water stress avoidance is calculated for each vegetated patch. Those growing season averages are then converted to quantile values based on 500 growing season simulations for each patch type, with 0 being the driest season and 1 being the wettest season for both soil moisture in bare patches and for water stress avoidance in vegetated patches (details given below). Next, the model generates $U_{g}(0,1)$, a random number between 0 and 1 drawn from a uniform distribution, for 
each patch. The random numbers are then used to update the patch states based on probabilistic transition functions, which define the probability of each possible transition as a continuous function of quantile value (see Figure 5). Details are provided for each of these steps below.

\section{<FIGURE 2>}

Vegetated patch persistence during the dry season is determined by both antecedent growing season soil moisture and grazing intensity. No daily water balance dynamics are simulated during the dry season. Instead, in order to determine perennial and annual patch persistence, the model generates another uniform random number, $U_{d}$, for each $A$ and $P$ patch. The random number is compared to a second set of probabilistic transition functions that depend on both the previous growing season stress avoidance quantile, and on grazing intensity quantile (see Figure 6 and details below). The model then updates the $A$ and $P$ patch states accordingly. The persisting $B$ and $B B$ patches, and updated $A$ and $P$ patches, represent the patch states at the end of the dry season and thus the beginning of the next growing season. $B$ patches that were not colonized during the growing season transition to $B B$ after one seasonal cycle. In the current rendering of the model, tree patches are fixed; the model does not include tree colonization or death.

\section{<FIGURE 3>}

\subsubsection{Water Balance Submodel}


The water balance submodel is fully described in Franz et al. (2012), and outlined in Appendix A; here we highlight key features of particular relevance to the study area and to the simulations presented in this report. Daily stochastic rainfall forcings, simulated by a marked Poisson process (Rodriguez-Itubre and Porporato, 2004) over a 90-day growing season, using mean storm arrival rate and mean daily storm depth derived from 50 years of daily records (Franz et al. 2012). This captures the highly pulsed rainfall patterns that drive complex soil moisture dynamics in the system. The 1-layer daily patch water balance equation includes Hortonian runoff $(R)$, yet in order to incorporate two-dimensional surface redistribution, calculations of $R$ contain a parameter $f r$, which controls the fraction of runoff that enters vegetation patches directly downslope. A value of $f r=0.4$ shows no preferential flow and a value near 0 has highly convergent flow in connected bare patches. This parameter allows the user to simulate different degrees of flowpath convergence in contiguous bare patches (and thus reduced run-on into vegetated patches), which has been observed to be an influential dynamic in the study site (Franz et al., 2012). Patch-specific mean daily water use rates are based on empirically derived evapotranspiration exponential decay constants $(k)$ for the three types of patches in the original model: $B, P$, and $T$. Grass roots are assumed not to extend beyond the cell, but tree roots extend into neighboring cells. The effect of neighbors on ET is modeled through a root-to-canopy ratio parameter $R C R$ in $T$ patches, where $R C R=1$ indicates no roots extending beyond the canopy (cell), and $R C R=3$ indicates tree roots occupy $100 \%$ of its four primary neighboring cells and $50 \%$ of its four diagonal neighbors. When roots extend into neighboring cells, those patches are assigned an effective $k$ value, which is the sum of fraction of roots multiplied by the patch type decay constant for the contributing neighbors. 
The water balance submodel was largely unchanged from (Franz et al., 2012), except that we reduced the size of the original patches from $4 \times 4 \mathrm{~m}$ to $2 \times 2 \mathrm{~m}$, and we modified it to include five patch types: degraded bare soil $(B B)$, bare soil $(B)$, annual grasses $(A)$, perennial grasses $(P)$, and trees $(T)$. The cell size was decreased to better align with empirical data for patch sizes. We added a distinction between $A$ and $P$ patches because we expected them to have different transition probabilities in response to soil moisture and herbivore pressure. The soil and vegetation parameter values for all patch types are described in Appendix A, Table A.1. Most parameters for $B, P$, and $T$ patches were empirically derived, estimated, or calibrated in (Franz et al., 2012). For the two new patch types, $B B$ and $A$ patches, we made the following assumptions regarding their differences from $B$ and $P$ patches, respectively. To model the $B B$ water balance, we assumed a $20 \%$ greater total runoff production during storm events than from the $B$ patch values given in Appendix A, Table A.1. With that assumption we derived a set of $B B$ runoff coefficients for the equation used to estimate runoff based on daily rainfall and intensity (Table A.1 in Appendix A). All remaining $B B$ parameters remain the same as $B$. To model the different water stress relationships of $A$, we assumed that $A$ patches experience full stress conditions and reduced evapotranspiration rates sooner during a soil moisture drydown, so we estimated that $A$ patch $\psi_{\text {wilt }}$ was $80 \%$ of the $P$ patch value of $-3 \mathrm{MPa}$, and $A$ patch $\psi *$ was $90 \%$ of the $P$ patch value of -0.045 MPa (Table A.1 in Appendix A). All remaining A parameter values were the same as $P$. For implementation verification, we tested and confirmed that the model conserves mass of water at both the cell and hillslope scales.

At each timestep, the water submodel calculates daily soil moisture for $B$ and $B B$ patches, and normalized daily water stress of each vegetation patch following Franz et al (2012), based on the 
probability distribution of soil moisture over the growing season, the daily average saturation, the wilting point saturation, the saturation at incipient stomatal closure. Daily water stress avoidance is also calculated, as 1 minus daily water stress. Appendix A provides an outline of the governing equations and procedures for the water balance submodel; fuller details are given in (Franz et al., 2012).

\subsubsection{Soil moisture availability and stress avoidance quantiles}

Patch transitions after the growing season are governed by average daily soil moisture in unvegetated patches, and average daily water stress experienced in vegetated patches, during the growing season. In general, vegetation colonization of $B$ or $B B$ patches is favored when soil moisture is greater, and vegetation persistence is favored when $A$ and $P$ patches avoid more water stress. The specific transition probabilities were derived as functions of soil moisture and water stress avoidance quantiles, rather than absolute values. In order to estimate the patchspecific growing season average soil water availability and stress avoidance quantiles, we simulated 500 growing seasons using the mean rainfall conditions. For each patch type separately, and for each season of the 500 simulated growing seasons, we computed the average daily soil water availability (mean daily soil moisture) in $B$ and $B B$ patches, and stress avoidance ( 1 minus daily average stress) in $A$ and $P$ patches. We then computed the empirical cumulative density function (CDF) of average daily water stress or average daily stress avoidance. We found that the 3 parameter generalized extreme value (GEV) distribution fit the empirical CDFs well (Figure 4). The GEV fit was expected given the rainfall simulation's marked Poisson process and the equations governing soil moisture, thus offering implementation verification of the submodel behavior. Using the GEV parameter fits, we computed soil moisture availability 
quantile $\left(Q_{s m}\right)$ and stress avoidance quantile $\left(Q_{s a}\right)$ values for each growing season model realization.

\section{<FIGURE 4>}

\subsubsection{Grazing intensity quantiles}

The water balance model does not explicitly determine biomass growth in each cell; we instead use grazing intensity quantiles $\left(Q_{g i}\right)$ to influence the probability that $A$ and $P$ patches persist or are extirpated. While grazing intensity affects vegetation during both the growing season and the dry season, the model incorporates the effect of grazing on patch persistence via grazing intensity transition probabilities only once during the seasonal cycle, during the dry season. The grazing intensity quantile and grazing-dependent transition probabilities are intended to phenomenologically capture the cumulative effects of grazing during and after the growing season. This approach is helpful because it can be parameterized using expert opinion, field monitoring, or remote sensing data, in which patch survival or extirpation becomes apparent in the following growing season. More mechanistic, biomass-based transition functions could incorporate physiological tolerance of herbivory into patch persistence probabilities, but our purpose is to develop a model that can be parameterized with coarser-scale season-to-season data on patch establishment and extirpation.

The $Q_{g i}$ values are applied uniformly to all vegetated cells in the domain, but do not represent an absolute number of herbivores in the domain. The quantiles instead represent relative grazing 
pressure experienced by each cell, or the extent to which forage is depleted in a given cell, which is independent of the proportion of the domain that is vegetated. For example, at $Q_{g i}=0.8$, each $P$ patch would be similarly grazed down and thus experience the same likelihood of extirpation, regardless of whether $10 \%$ or $100 \%$ of the domain was vegetated. The quantiles therefore represent a "per-cell" grazing rate, which in the context of optimal foraging theory would imply an ideal free distribution of herbivores (Behnke et al., 2011), achieved by herds moving over an area larger than the modeled hillslope. In practice, the grazing intensity, i.e., the extent to which vegetation in each patch is depleted, is largely determined by herder decision-making. Herders customarily make migration decisions based on local forage height and density, in concert with information about long-distance grazing areas and other social and economic considerations. Thus, a high $Q_{g i}$ is analogous to herders deciding to continue grazing in the domain until forage is more severely depleted.

The $Q_{g i}$ values vary between 0 and 1 , where 0 represents no grazing by livestock or wildlife, and thus no influence of herbivory on patch persistence. We define $Q_{g i}=0.2$ to represent the expected per-cell impact of grazing by free roaming wildlife populations in the area. We define $Q_{g i}=0.5$ as representing the historical rules used by herders to decide when to move to another area, when multiple long-distance dry-season grazing areas were accessible. We define values of 0.6 and 0.8 to represent the current range of forage depletion that occurs at the study site as a result of herders' decisions to delay or forego long-range herd movements because of the costs, risks, and restrictions to mobility. A $Q_{g i}$ value $=1$ represents extremely high per patch grazing intensity that will basically remove all edible above-ground biomass in a patch. Grazing 
pressure is applied equally to $A$ and $P$ patches (no grazing preferences represented), but transition probabilities differ for the patch types.

\section{<FIGURE 5>}

\subsubsection{Transition probabilities}

The growing season transition probabilities for each patch type were based on water balance quantiles, and are summarized and illustrated in Figure 5. The x-axis in Figure 5 is the computed soil moisture availability quantile $\left(Q_{s m}\right)$ for $B B$ and $B$ patches (Figure $5 \mathrm{a}$ and $\mathrm{b}$ ) and stress avoidance quantile $\left(Q_{s a}\right)$ for $A$ and $P$ patches (Figure $5 \mathrm{c}$ and d). The y-axis specifies ranges for each possible state transition, whose widths are proportional to their probability. This is used to match to the uniform random number $U_{g}(0,1)$, which is drawn for each patch in the model domain. Using the patch specific quantile value and $U_{g}(0,1)$, the new patch states were determined by plotting the values on the graph and assigning the new patch type accordingly. The parameterization, based on hypothetical and observed cases, will be discussed in the next section.

The dry-season transition probabilities apply to $A$ and $P$ patches only, and are used to determine the probability of a dry-season patch change to $B$. They depend on both the growing-season stress avoidance quantile $Q_{s a}$ and the grazing intensity quantile $Q_{g i}$ values, and are illustrated in 
Figure 6. The probabilities are implemented as threshold values to determine transitions as follows: for each $A$ and $P$ patch, a dry-season uniform random number $U_{d}(0,1)$ is drawn. The cell's $U_{d}$ value is compared to the threshold value (represented as a color in Figure 6) for its particular $Q_{s a}$ and the simulation's fixed $Q_{g i}$. The patch transitions to $B$ if $U_{d}$ is greater than the comparison value. The transition from $B$ to $B B$ during the dry season is deterministic based on whether the patch was already $B$ at the beginning of the growing season, following Figure 3 . All $T$ patches always remain $T$ patches.

\section{〈FIGURE 6>}

\subsubsection{Transition probability parameterization}

Empirical parameterization of the transition probability functions would require a tremendous amount of data from grazing intensity manipulations over many years, and such data are not available. This problem is not uncommon in constructing ecological simulation models, in which case emergent-level patterns (Grimm et al., 2005), scientific expert opinion (Koniak and Noy-Meir, 2009; Perera et al., 2012), and local expert knowledge (Wendt and Starr, 2009; Fernández-Giménez and Estaque, 2012; Oba, 2012) offer informational resources to generate approximate estimates of parameters. Accordingly, to construct approximations of the growingseason and dry-season transition functions, we integrated patch-level transition frequencies observed on $2450 \mathrm{~m}$ transects over 7 years at ambient grazing intensities at the study site (King et al,, unpublished manuscript), as well as ecological and local herding expert observations of herbaceous dynamics in response to changing rainfall and grazing intensities. 
We first estimated growing-season transition probabilities as linear or segmented linear functions of water availability/stress avoidance quantiles (Figure 5). These approximations were based on general observations of growing-season herbaceous dynamics across multiple sites over 15 years of ecological research in the region (King, personal observations). We also conducted seven bouts of vegetation monitoring, between 2006 and 2013, along permanent transects at the study site. Appendix B explains how those transect data were used to help calibrate our estimations of season-to-season patch transition frequencies (data evaluation and model output verification).

We used five hypothetical rainfall-grazing scenarios (explained in Appendix C) to structure our derivation of dry-season transition probability functions. The five scenarios represent end member cases, and expected outcomes were based on the observations of the authors and discussions with community members (data evaluation). By using the five hypothetical scenarios and an iterative process involving model output verification and model sensitivity analysis, we were able to identify a set of transition matrix parameter values from model simulations. For each scenario, we hypothesized a general expected hillslope-scale outcome, percent vegetation cover $(A+P+T)$, that would arise from three consecutive seasons under that scenario. We systematically varied transition rates and examined the sensitivity of 3-year outcomes to variability in transition functions (Appendix C). This allowed us to calibrate the transition probabilities by identifying values that simultaneously satisfied the 3 -season expectations from all scenarios. Since each scenario was based on different grazing and water availability quantiles, each determined a set of points in Figures 5 and 6 . Next, we connected the points with lines in order to complete the transition matrices illustrated in Figures 5 and 6 . The 
graphs were then discretized with a resolution of 0.001 forming 1001 by 1001 lookup tables, which were then used to assign transitions in the model simulations. By considering only general grass vs. bare patch types in this process, and analyzing sensitivity over a short threeseason time horizon, we sought to avoid overparameterization and to keep the calibration based on time frames of our empirical data.

\subsection{Simulation experiment and model analysis}

We ran a simulation experiment using different combinations of grazing intensity $\left(Q_{g i}\right)$ and the two parameters that affect cell-cell interactions in the water balance submodel: $f r$ and $R C R$. We ran the model for a $200 \mathrm{~m}$ by $200 \mathrm{~m}$ domain, consisting of 100 by 100 grid cells, for 200 seasonal cycles. All simulations used the same simulated 200-season stochastic daily rainfall sequence. The landscapes were all initiated with the same random distributions of $10 \% T$ cover, and $22.5 \% B B, B, A$, and $P$.

Building on previous analysis of the hydrological submodel sensitivity to changes in $f r$ and $R C R$ (Franz et al., 2012), we conducted a sensitivity analysis of the relative influence of grazing pressure versus $f r$ and $R C R$ on the full MVUACHACHE model behavior. To do so, we ran sets

of 6 simulations for pairwise combinations of different $R C R$ and $f r$ values $(R C R=1$ and 3 , and $f r$ $=0.01,0.2$, and 0.4$)$. We repeated the sets of simulations at 6 different grazing intensity quantiles, from 0 to 1 in increments of 0.2 , for a total of 36 simulations. 
We also conducted a sensitivity analysis to determine the relative influence of variability in the growing season transition rates for persistence/recolonization of $B$ and $B B$ patches. These variables were chosen because the field measurements used for calibration did not reliably distinguish between $\mathrm{B}$ and $\mathrm{BB}$, and thus we had the most uncertainty for those rates (data evaluation). We ran a series of 32 -year simulations on a reduced domain size ( $25 \times 25$ cells), systematically varying the probability of bare patch persistence in the $B B$ and $B$ transition functions. This was accomplished by modulating the transition probability at the highest soil moisture quantile, $Q_{s m}=1$, by 5 or $10 \%$ while the transition probability at $Q_{s m}=0.25$ was held constant, and recalculating the linear function between those two points. We explored model outputs using 8 different $B B$-to- $B B$ transition functions, in which $\mathrm{p}\left(B B \mid B B, Q_{s m}=1\right)$ ranged from 0.99 to 0.41 . These simulations were conducted for each of three different $B$-to- $B$ transition functions, which were modulated using the same procedure, with $\mathrm{p}\left(B \mid B, Q_{s m}=1\right)$ set to $0.89,0.81$, and 0.31. Figure 7 illustrates the scenarios used. All simulations were run for each level of $Q_{g i}$ from 0 to 1 in increments of 0.2 . We averaged and compared the fractional vegetation cover $(A+P+T)$ for years 25-32 from each simulation.

\section{<FIGURE 7>}

\subsection{Model corroboration}

The water balance submodel, which was largely unmodified, was calibrated and validated in previous work using data from our study site (Franz et al., 2010, 2012). To evaluate the full 
model's simulation results at the domain/hillslope scale, our model output corroboration procedure was intended to assess whether our attempt to couple the water submodel with grazing-specific transition functions resulted in behaviors (extent and temporal changes herbaceous vegetation cover) that were plausible and within the bounds of expectations and empirical observations. Our validation was constrained to this general behavior assessment because of the limited empirical data available at the hillslope scale.

We evaluated the concordance between the model outputs of fractional cover and empirical hillslope-scale fractional patch cover measurements from 7 years of monitoring data from permanent transects on a hillslope at the field site. In the field study, we used a more complex characterization of vegetated patches, but the field data and model outputs were made comparable by summing the percent cover of all non-bare patches $(A+P+T$ in the model; many vegetation classes in the field data) to calculate the total vegetation patch cover. We also compared empirical season-to-season variability in patch cover at the field site to the simulated dynamics. At the field site, grazing intensity on the hillslope was governed by local herders' decision-making and livestock densities. The model's grazing intensity quantiles and transition functions were calibrated such that grazing intensity at the study site corresponded to $Q_{g i}=0.6$ to 0.8. The empirical validation was thus constrained to assess whether the model's predictions at those grazing intensities corresponded reasonably with metrics from the field site.

\section{Results}


In the following sections we present the simulation results and describe the temporal dynamics of fractional cover of the different simulated patch types; we examine the findings from the sensitivity analysis and validation procedure that compared simulated and observed fractional cover; and present an analysis of landscape organization and spatial patterning.

\subsection{Modeled temporal dynamics}

In the first simulations to test the model's performance, we limited the potential parameter space by setting $R C R=3$ and $f r=0.1$, which reflect likely conditions at the study site (Franz et al., 2012). We ran six different simulations, in which we varied $Q_{g i}$ from 0 to 1.0 , in increments of 0.2 , and allowed the system to evolve for 200 growing season cycles.

The simulated growing season total rainfall for the 200 growing seasons is shown in Figure 8a (mean $178=\mathrm{mm} /$ season, range $=50$ to $360 \mathrm{~mm}$, coefficient of variation $=0.32$ ). The simulation results for each $Q_{g i}$ level are show in Figure 8b-8g. These plots show the fractional cover at the end of the rainy season and at the end of the dry season for each seasonal cycle. A general inspection of trends across grazing intensities reveals that with increasing grazing intensity, the overall proportion of $B B$ steadily increased and $P$ decreased, which is consistent with expected system behavior. The trends of $A$ and $B$ patches, compared across simulations, reveal that their fractional cover was less sensitive to grazing intensity, and these patch types tended to constitute a smaller proportion of the land cover. The ratio of perennial to annual herbaceous cover declined as grazing intensity increased, but this pattern arose not because annual vegetation was 
'replacing' perennial vegetation, but because absolute perennial cover decreased with grazing intensity.

In the complete absence of grazing-induced patch mortality $\left(Q_{g i}=0\right.$, Figure $\left.8 b\right)$, the system does not evolve toward a completely vegetated state. This finding agrees with expectations; both the low mean annual precipitation as well as the high coefficient of variation in rainfall at the site are expected to limit productivity, resulting in a partially vegetated, semi-desert landscape. At the other extreme, under the heaviest grazing intensity $\left(Q_{g i}=1\right.$, Figure $\left.8 \mathrm{~g}\right)$, perennial patch cover remained below $10 \%$ throughout the simulation, but we did not see a complete, persistent loss of perennial patches. This represents a reasonable model behavior, given the way that grazing pressure was modeled. Extreme grazing pressure implies total aboveground biomass removal, which perennial grasses can withstand because of their energy allocation to roots.

\section{<FIGURE 8>}

In addition to the tradeoffs between $P$ and $B B$ seen in response to grazing, we also see tradeoffs across the time series within simulations. In the 0 to $0.6 Q_{g i}$ simulations (Figure $8 \mathrm{~b}-8 \mathrm{e}$ ), we see infrequent switches in $P$ and $B B$ fractional cover (at $\sim 15$ to 50 -season intervals), where one increases and the other decreases by about $20 \%$. These may represent alternate attractors, reinforced by water-soil-plant feedbacks represented in the model. Since the switches are synchronized across simulations, we may assume that switches are triggered by rainfall patterns, rather than a result of chance extreme transition probabilities. The switches appear to 
temporally follow extremes in multi-season rainfall totals (i.e., periods containing several wetter seasons or several drier seasons), with transition periods between the states occurring over approximately 10 seasonal cycles. At the highest $Q_{g i}$ levels (Figure $8 \mathrm{f}$ and $8 \mathrm{~g}$ ), the amplitude of the $B B$ switches is dampened relative to shorter term fluctuations, while the $P$ switches are smaller in amplitude but still distinct when compared to shorter term fluctuations. The switching between alternative attractors was not an expected outcome, but represents an ecologically plausible behavior of the system.

\subsection{Model analysis and validation of simulated fractional covers}

In a previous study of the static water balance submodel, the ecohydrological parameters $R C R$ and $f r$ were shown to affect hillslope water use efficiency. In the dynamic MVUACHACHE model, those effects were expected to form feedbacks with vegetation that would result in different levels of hillslope vegetation cover. To assess the relative impacts of $R C R, f r$, and grazing intensity on model behavior, we compared the average fractional cover of all vegetated patches $(A+P+T)$ from 36 simulations that had varying levels of $R C R, f r$, and grazing intensity

(Figure 9a). The parallel curves in Figure 9a illustrate that: (1) the influence of grazing pressure was greater than, but the same order of magnitude as, the influence of ecohydrological parameters; and (2) that the effects of the two classes of parameters were largely additive. Each $R C R$-fr combination showed a similar declining trend in vegetated patch cover with increasing grazing intensity quantile (from $57-71 \%$ at $Q_{g i}=0$ to $25-35 \%$ at $Q_{g i}=1.0$ ). Within each grazing intensity quantile from 0 to 0.6 , the combination of parameters representing the highest hillslope water use efficiency $(f r=0.4, R C R=1)$ resulted in about $15 \%$ greater absolute vegetated patch 
cover than the least water use efficient scenario $(f r=0.01, R C R=3)$. At higher grazing intensities, the trend persisted but the absolute differences between ecohydrological scenarios diminished.

Having used field estimates of patch-specific transition frequencies to calibrate the model, we sought to validate its emergent behavior by evaluating the correspondence between the simulated landscape-level patterns of fractional cover (Figure 9a) and empirical measurements from the study site (Figure 9b). Over 7 censuses of permanent transects at the study site, the average hillslope vegetation cover (equivalent to $A+P+T$ patches) varied between 22 and $36 \%$, except for one census when fractional cover reached $82 \%$ following an extended El Niño rainy period. The temporally averaged vegetation cover (mean of the seasonal means) was $36.3 \% \pm 20.7$ s.d. (Figure 9b). We then compared the empirical average cover to the simulations by plotting the empirical mean as a gray horizontal line in Figure 9a. We expected the empirical landscape conditions to correspond to $R C R=3, f r=0.1$ to 0.2 , and $Q_{g i}=0.6$ to 0.8 . The simulations with $Q_{g i}=0.8$ and lower $f r$ values corresponded reasonably well to the field data.

\section{<FIGURE 9>}

When we examined the model output sensitivity to variability in $B B$ and $B$ patch persistence/ recolonization rates in the growing season, we found that large changes in $B$ patch persistence rates had little effect on hillslope fractional vegetation cover, but vegetation cover was quite sensitive to changes in $B B$ patch persistence rates. Figure 10a, b, and c show hillslope vegetation 
cover at three different $B$ patch persistence rates (corresponding to the solid and dashed black lines in Figure 7b). There is very little shift in average cover between the three panels, indicating little sensitivity to $B$ persistence calibration. The colored lines within each Figure 10 panel, on the other hand, show the sensitivity to varying $B B$ persistence rates, and these led to stronger effects on cover. A $5 \%$ increase in $\mathrm{p}\left(B B \mid B B, Q_{s m}=1\right)$, the parameter used to generate the different transition function variants, resulted in decreases of hillslope vegetation cover of about 10 to $20 \%$, depending on other scenario conditions (difference between cyan and light blue lines in

Figures $10 \mathrm{a}, \mathrm{b}$, and c). A $5 \%$ decrease in $\mathrm{p}\left(B B \mid B B, Q_{s m}=1\right)$ had a smaller effect, increasing hillslope cover by about 5-10\% across the $3 \mathrm{~B}$ patch persistence scenarios (difference between cyan and green lines in Figure 10a, b, and c). Varying the BB and B transition functions did not, however, change the behavior of the model qualitatively.

\section{<FIGURE 10>}

\subsection{Spatial dynamics and landscape organization}

Figure 11 presents a representative sample of simulated hillslopes; we did not observe any obvious regular pattern formation. We further examined simulation sets with all $R C R-f r$ permutations for $Q_{g i}=0.2$ and $Q_{g i}=0.8$ to look for other hillslope-scale spatial patterns that emerged as the landscapes evolved. From each simulation, we calculated the $A+P+T$ fraction for each $10 \mathrm{~m}$ contour (horizontal) band across the simulated domain (Figure 12). At low grazing intensity $\left(Q_{g i}=0.2\right.$, Figure $\left.12 \mathrm{a}\right), R C R$ strongly influenced vegetation cover in the top $100 \mathrm{~m}$ of the domain, which can be seen by comparing pairs of lines for the same fr. More extensive root 
competition imposed by trees ( $R C R 3$ vs 1 ) resulted in 10-15\% lower vegetation cover (distance between dark blue and light blue points, between green and cyan points, and between yellow and orange points). In contrast, in the lower $100 \mathrm{~m}$ of the hillslope, the fractional vegetation cover appeared more strongly governed by $f r$, with the two $f r=0.01$ simulations displaying about 5-10\% less vegetation cover than the simulations with less flowpath convergence. Figure $12 \mathrm{~b}$ illustrates that the same differential effects of $R C R$ and $f r$ at higher grazing intensity $\left(Q_{g i}=0.8\right)$, but with smaller absolute effect sizes.

<FIGURE 11>

\section{<FIGURE 12>}

\section{Discussion}

As we reflect on our first explorations of model behaviors, we note interesting outcomes, identify limitations of the study, and also find great scope for future model explorations that modify or elaborate on key parameters.

\subsection{Effects of grazing pressure}


Modeling grazing pressure as a per-patch grazing intensity, rather than a stocking rate of animal density per landscape area, allows us to envision grazing intensity as a reflection of herder decision-making. Herders indeed report using indicators such as typical grass height (as well as weather predictions, water availability, animal condition, etc.) to decide how long to continue grazing in an area before seeking better forage elsewhere (e.g., Fernandez-Gimenez, 2000; Fernández-Giménez and Estaque, 2012; Oba, 2012; Ghorbani et al., 2013). With increasing consensus, studies are revealing that livestock-driven land degradation in traditionally mobile pastoralist systems arises from constraints to mobility, rather than intense yet mobile rangeland use (Adriansen, 2008; Coughenour et al., 2008; Homann et al., 2008; Butt, 2010). With grazing pressure parameterized in a way that relates to herder decisions, this creates the exciting opportunity to compare different scenarios of herd mobility via different formulations of grazing pressure. Additionally, it would be possible to couple MVUACHACHE with a human decisionmaking ABM module (An, 2012), which would allow the exploration of both social and environmental drivers and responses to change in dryland pastoralist systems.

One limitation of the current representation of grazing pressure is that it only represents the cumulative depletion of forage. While that representation has the most straightforward connection to phenomenological vegetation data, it limits our ability to understand the consequences of herd densities and timing of grazing. When calibrating the transition probabilities with field data and expert opinion, we implicitly assumed that for $Q_{g i}$ values greater than 0.2 (which represented only wildlife foraging), the density of livestock on the landscape was similar to that present in the study system today, and thus $Q_{g i}$ was related to the duration of 
grazing into the dry season. By representing grazing intensity as total consumption instead of consumption per unit time, the model does not distinguish between the effects of a very dense herd consuming all vegetation quickly versus a small herd consuming vegetation more slowly. These would be expected to have different physiological consequences on grass persistence, since belowground carbon reserves can only be built up during the growing season. We expect that this explains why, despite extremely heavy consumption of aboveground biomass at $Q_{g i}=1$, the simulations do not result in persistent vegetation collapse. There is an implicit assumption that the extra grazing intensity occurred after the growing season.

In reality, mobility in our system is heavily constrained today, and distant grazing access can vary from year to year and from family to family (King, personal observation). If herders are unable to move their livestock in a previous dry season, and those animals are present in full numbers at the beginning of the next growing season, they can have a particularly strong negative effect on growing-season productivity. On the other hand, when herds are able to move away during the dry season, their delayed return in the following growing season may allow grasses to produce more forage before grazing ensues. In future work, we intend to develop a grazing parameterization that distinguishes growing-season and dry-season impacts on vegetation, and allows potential for feedback between grazing pressure in the two seasons. Incorporating these effects may qualitatively change the model behavior and lead to perennial vegetation collapse.

\subsection{Spatial pattern formation}


The simulations revealed some hillslope-scale pattern formation; vegetation was typically denser in the lower $100 \mathrm{~m}$ of the hillslope domain. We infer that in the upper $100 \mathrm{~m}$ of the domain, belowground competition and water use strongly limit vegetation cover, creating more cells with high water stress and therefore low probabilities of patch establishment and success. Further downhill, it is likely that patches are getting enough Hortonion flow run-on from the upper reaches, creating effective precipitation levels that ameliorate the limiting effects of ET demand. We did not record mean water stress at each season for each cell as a model output; doing so would help understand whether this hillslope-scale vegetation patterning is due to the higher effective precipitation effect of runoff. Also, in future exploration of the model, we intend to alter rainfall amounts and arrival rates, which we would expect to result in upward or downward shifts in the switching point if this is indeed the driver of the pattern observed. In general, understanding the relative contributions of different factors (e.g., biotic interactions vs. environmental gradients; local- vs. landscape-scale effects) to pattern formation is a vibrant field of inquiry in complexity studies today (e.g., HilleRisLambers et al., 2001; Feagin et al., 2005; Scanlon et al., 2007; Meron, 2012; Baudena et al., 2013; Stewart et al., 2014). This model can contribute to that field through future work that focuses more specifically on the characteristics of spatial patterns that emerge in response to multiple types of drivers and interactions.

Relating spatial dynamics to ecosystem function, we found that varying the patterns of hillslope water redistribution via the $f r$ parameter, which determines the degree of flowpath convergence and channelization through unvegetated cells, had substantial impacts on mean vegetation cover. In this study, $f r$ was fixed throughout the 200 seasonal cycles, but in reality, we expect feedbacks between water redistribution and vegetation cover. Our observations and measurements of 
highly variable degrees and forms of erosion in different parts of a single hillslope (King, unpublished manuscript) suggest that $f r$ is not likely to be homogenous over an entire hillslope. We would therefore like to allow $f r$ to evolve and create feedbacks with vegetation, such that it can increase or decrease in response to localized vegetation cover within the domain. This could lead to quite different spatial patterning in model scenarios. Also, we could introduce hysteresis that typically happens with soil erosion and gully formation, by having $f r$ degrade more easily than it recovers in response to vegetation shifts.

\subsection{Abiotic drivers}

While in this study we explored the effects of varying grazing intensity and water redistribution, the study utilized only one simulated 200-season daily rainfall pattern, which emulated empirical precipitation trends from the field site. Generating rainfall patterns that altered MAP, variation in MAP, and rainfall arrival patterns would allow us to explore whether perennial vegetation collapses at some threshold level of water limitation or variability. Another limitation of the model is that only current-season rainfall is used to determine patch transitions, yet "memory effects" of rainfall and productivity from previous seasons have been shown influence vegetation responses (Schwinning et al., 2004; Monger et al., 2015). Nevertheless, the multi-decadal switches appeared to occur in response to multi-season dry and wet periods, rather than single extreme seasons, suggesting that memory effects are emerging in the system's behavior. As we continue to monitor long-term transects, our analyses aim to detect any such lag effects, which could be used to refine the model calibration or explicitly incorporated into the model via transition probability functions. 


\subsection{Model performance}

The development of MVUACHACHE was inspired by the pattern-oriented modeling approach advocated by Grimm et al. (2005), utilizing both mechanistic and phenomenological understanding to iteratively hone a model toward its intended functionality. The model was successful in coupling a mechanistic water balance CA submodel with patch transition probabilities governed by growing-season soil water availability and estimated impacts of grazing intensity. We calibrated the model using the frequencies with which individual patch transitions tended to occur at the site, and we found that the resulting landscape-scale dynamics were within plausible and observed ranges of landscape-scale fractional cover at the site. Also, the model and empirical data showed similar degrees of variability, with one notable exception. We observed that vegetation cover exceeded $80 \%$ in response to a high rainfall season in 2007 , yet we never saw such dramatic spikes in fractional cover in simulations. One possible reason for the discrepancy is that our empirical cover measurements included two highly opportunistic ephemeral species, Tribulus terrestris (Zygophyllaceae) and Tragus berteronianus (Poaceae), whose dramatic and short-lived flushes in response to rainfall were not considered when estimating transition probability functions.

We note that the validation process must be considered as only partial, as we have been constrained to empirical measurements under ambient grazing intensities and for relatively short durations of time compared to the decadal switches and variability exhibited by the model. Our conceptual understandings of the water-soil-plant feedbacks that influence the self-organization 
of vegetation in response to different abiotic trends is compatible with vegetation community shifts triggered by multi-season rainfall anomalies (Sala et al., 2012, Collins et al., 2014), and there are long-term empirical studies that show such community fluctuations (e.g., Fuhlendorf et al., 2001; Browning et al, 2011; Bagchi et al., 2103). Our model did not explicitly represent possible mechanisms by which multi-season rainfall anomalies may affect vegetation dynamics. Through further model exploration with different contrived rainfall scenarios, we hope to identify whether the spatial ecohydrological design of the model, or the phenomenological transition properties, or both, are capturing the cumulative effect of multiple-season anomalies to create this emergent temporal dynamic.

More generally, both our simulation and empirical results, as well as the growing number of long-term studies of dryland vegetation responses to rainfall and grazing (e.g., Miehe et al., 2010; Browning et al., 2011; Bagchi et al., 2013), indicate that fractional herbaceous cover is often highly labile in drylands, offering a cautionary illustration of the potential for short-term studies of rangeland dynamics to be misleading. Even precipitous declines in perennial grass cover over several seasons may not indicate a loss of ecosystem resilience, nor would a substantial increase in cover necessarily be an indicator of long-term ecological recovery (Briske et al., 2008, Bagchi et al, 2012). Despite wide recognition that rainfall and grazing are key determinants of the structure and function of drylands, we still have a limited understanding of their relative importance, and how that varies with biogeographical context (Ruppert et al, 2015). Context-specific models such as the one we have developed, remote sensing through time, and long-term grazing exclosures will prove highly valuable for further understanding the resilience 
and future environmental responses of these ecosystems, which provide critical livelihood resources for pastoralists.

\section{Acknowledgments}

We gratefully acknowledge the cooperation and assistance of Anthony Lekutaas Parsaroi and all our field assistants, and the management and residents of Koija Group Ranch. Three anonymous reviewers provided constructive comments on the manuscript. This research was conducted with permission of the Government of Kenya (Permit NCST/RRI/12/1/MAS/108), and with support from the U.S. National Science Foundation, Grant No. 1313659.

\section{References}

Adriansen, H.K., 2008. Understanding pastoral mobility: the case of Senegalese Fulani. Geographical Journal, 174:207-222.

An, L., 2012. Modeling human decisions in coupled human and natural systems: Review of agent-based models. Ecological Modelling, 229:25-36.

Augusiak, J., Van den Brink, P. J., \& Grimm, V., 2014. Merging validation and evaluation of ecological models to 'evaludation': a review of terminology and a practical approach. Ecological Modelling, 280, 117-128. 
Bagchi, S., Briske, D. D., Wu, X. B., McClaran, M. P., Bestelmeyer, B. T., \& FernándezGiménez, M. E., 2012. Empirical assessment of state-and-transition models with a longterm vegetation record from the Sonoran Desert. Ecological Applications, 22(2), 400411.

Bagchi, S., Briske, D.D., Bestelmeyer, B.T. and Ben Wu, X., 2013. Assessing resilience and state-transition models with historical records of cheatgrass Bromus tectorum invasion in North American sagebrush-steppe. Journal of Applied Ecology, 50:1131-1141.

Bar Massada, A., Carmel, Y., Koniak, G. and Noy-Meir, I., 2009. The effects of disturbance based management on the dynamics of Mediterranean vegetation: a hierarchical and spatially explicit modeling approach. Ecological Modelling, 220: 2525-2535.

Baudena, M., von Hardenberg, J. and Provenzale, A., 2013. Vegetation patterns and soilatmosphere water fluxes in drylands. Advances in Water Resources, 53:131-138.

Behnke, R.H., Fernandez-Gimenez, M.E., Turner, M.D. and Stammler, F., 2011. Pastoral migration: mobile systems of livestock husbandry. In: E.J. Milner-Gulland, J.M. Fryxell and A.R.E. Sinclair (Editor), Animal migration: a synthesis. Oxford University Press, Oxford, pp. 144-171.

Bestelmeyer, B. T., Duniway, M. C., James, D. K., Burkett, L. M., \& Havstad, K. M., 2013. A test of critical thresholds and their indicators in a desertification-prone ecosystem: more resilience than we thought. Ecology Letters, 16(3), 339-345.

Borgogno, F., D'Odorico, P., Laio, F. and Ridolfi, L., 2009. Mathematical Models Of Vegetation Pattern Formation In Ecohydrology. Reviews of Geophysics, 47:36. 
Breshears, D.D., Myers, O.B. and Barnes, F.J., 2009. Horizontal heterogeneity in the frequency of plant-available water with woodland intercanopy-canopy vegetation patch type rivals that occuring vertically by soil depth. Ecohydrology, 2:503-519.

Briske, D., Bestelmeyer, B., Stringham, T., \& Shaver, P. 2008. Recommendations for development of resilience-based state-and-transition models. Rangeland Ecology \& Management, 61(4), 359-367.

Browning, D.M., Duniway, M.C., Laliberte, A.S. and Rango, A., 2011. Hierarchical analysis of vegetation dynamics over 71 years: soil-rainfall interactions in a Chihuahuan Desert ecosystem. Ecological Applications, 22:909-926.

Butt, B., 2010. Pastoral resource access and utilization: Quantifying the spatial and temporal relationships between livestock mobility, density and biomass availability in southern Kenya. Land Degradation \& Development, 21:520-539.

Catley, A., Lind, J. and Scoones, I., 2013. Development at the margins: pastoralism in the horn of Africa. In: A. Catley, J. Lind and I. Scoones (Editor), Pastoralism and Development in Africa: Dynamic Change at the Margins. Routledge, New York, pp. 1-26.

Clapp, R.B. and Hornberger, G.M., 1978. Empirical equations for some soil hydraulic properties. Water Resources Research, 14:601-604.

Collins, S.L., Belnap, J., Grimm, N.B., Rudgers, J.A., Dahm, C.N., D'Odorico, P., Litvak, M., Natvig, D.O., Peters, D.C., Pockman, W.T., Sinsabaugh, R.L. and Wolf, B.O., 2014. A Multiscale, Hierarchical Model of Pulse Dynamics in Arid-Land Ecosystems. Annual Review of Ecology, Evolution, and Systematics, 45:397-419. 
Coughenour, M., Behnke, R., Lomas, J. and Price, K., 2008. Forage Distributions, Range Condition, and the Importance of Pastoral Movement in Central Asia - A Remote Sensing Study. In: R. Behnke (Editor), The Socio-Economic Causes and Consequences of Desertification in Central Asia. Springer Netherlands, pp. 45-80.

Deblauwe, V., Barbier, N., Couteron, P., Lejeune, O. and Bogaert, J., 2008. The global biogeography of semi-arid periodic vegetation patterns. Global Ecology and Biogeography, 17:715-723.

Dingman, L. S., 2002, Physical Hydrology, 2nd ed.. Prentice-Hall, Upper Saddle River, New Jersey, USA.

Feagin, R., Wu, X., Smeins, F., Whisenant, S. and Grant, W., 2005. Individual versus community level processes and pattern formation in a model of sand dune plant succession. Ecological Modelling, 183:435-449.

Fernandez-Gimenez, M.E., 2000. The role of mongolian nomadic pastoralists'ecological knowledge in rangeland management. Ecological Applications, 10:1318-1326.

Fernández-Giménez, M.E. and Estaque, F.F., 2012. Pyrenean pastoralists’ ecological knowledge: documentation and application to natural resource management and adaptation. Human Ecology, 40:287-300.

Franz, T.E., Caylor, K.K., Nordbotten, J.M., Rodriguez-Itubre, R.I. and Celia, M.A., 2010. An ecohydrological approach to predicting regional woody species distribution patterns in dryland ecosystems. Advances in Water Resources, 33:215-230. 
Franz, T.E., Caylor, K.K., King, E.G., Nordbotten, J.M., Celia, M.A. and Rodríguez-Iturbe, I., 2012. An ecohydrological approach to predicting hillslope-scale vegetation patterns in dryland ecosystems. Water Resources Research, 48:W01515.

Fuhlendorf, S.D., Briske, D.D. and Smeins, F.E., 2001. Herbaceous vegetation change in variable rangeland environments: The relative contribution of grazing and climatic variability. Applied Vegetation Science, 4:177-188.

Ghorbani, M., Azarnivand, H., Mehrabi, A.A., Jafari, M., Nayebi, H. and Seeland, K., 2013. The role of indigenous ecological knowledge in managing rangelands sustainably in northern Iran. Ecology and Society, 18:15.

Grimm, V., Revilla, E., Berger, U., Jeltsch, F., Mooij, W.M., Railsback, S.F., Thulke, H.-H., Weiner, J., Wiegand, T. and DeAngelis, D.L., 2005. Pattern-Oriented Modeling of Agent-Based Complex Systems: Lessons from Ecology. Science, 310:987-991.

Grimm, V., Berger, U., DeAngelis, D. L., Polhill, J. G., Giske, J., \& Railsback, S. F., 2010. The ODD protocol: a review and first update. Ecological modelling, 221(23), 2760-2768.

Grimm, V., Augusiak, J., Focks, A., Frank, B.M., Gabsi, F., Johnston, A.S.A., Liu, C., Martin, B.T., Meli, M., Radchuk, V., Thorbek, P. and Railsback, S.F., 2014. Towards better modelling and decision support: Documenting model development, testing, and analysis using TRACE. Ecological Modelling, 280:129-139.

HilleRisLambers, R., Rietkerk, M., van den Bosch, F., Prins, H.H.T. and de Kroon, H., 2001. Vegetation pattern formation in semi-arid grazing systems. Ecology, 82:50-61. 
Homann, S., Rischkowsky, B. and Steinbach, J., 2008. The effect of development interventions on the use of indigenous range management strategies in the Borana Lowlands in Ethiopia. Land Degradation \& Development, 19:368-387.

Illius, A. W. and O'Connor, T. G., 1999. On the relevance of nonequilibrium concepts to arid and semiarid grazing systems. Ecological Applications 9:798-813.

Jeltsch, F., Milton, S., Dean, W., Rooyen, N.v. and Moloney, K., 1998. Modelling the impact of small-scale heterogeneities on tree-grass coexistence in semi-arid savannas. Journal of Ecology, 86:780-793.

Jeltsch, F., Milton, S.J., Dean, W.R.J. and Van, R.N., 1997a. Analysing shrub encroachment in the southern Kalahari: A grid-based modelling approach. Journal of Applied Ecology, 34:1497-1508.

Jeltsch, F., Milton, S.J., Dean, W.R.J. and Van Rooyen, N., 1997b. Simulated pattern formation around artificial waterholes in the semi-arid Kalahari. Journal of Vegetation Science, 8:177-188.

Jeltsch, F., Milton, S.J., Dean, W.R.J. and VanRooyen, N., 1996. Tree spacing and coexistence in semiarid savannas. Journal of Ecology, 84:583-595.

Kaye-Zwiebel, E. and King, E., 2014. Kenyan pastoralist societies in transition: varying perceptions of the value of ecosystem services. Ecology and Society, 19: 17.

Kéfi, S., Eppinga, M.B., de Ruiter, P.C. and Rietkerk, M., 2010. Bistability and regular spatial patterns in arid ecosystems. Theoretical Ecology, 3:257-269. 
Kefi, S., Rietkerk, M., Alados, C.L., Pueyo, Y., Papanastasis, V.P., ElAich, A. and de Ruiter, P.C., 2007. Spatial vegetation patterns and imminent desertification in Mediterranean arid ecosystems. Nature, 449:213-U215.

King, E.G., 2008. The dynamics of Sansevieria intermedia in degraded Kenyan drylands: regime shift or resilience mechanism? Hohhot, China: Proceedings of the VIIIth International Rangeland Congress.

King, E.G., Franz, T.E. and Caylor, K.K., 2012. Ecohydrological interactions in a degraded twophase mosaic dryland: implications for regime shifts, resilience, and restoration. Ecohydrology, 5: DOI: 10.1002/eco.1260.

Koniak, G. and Noy-Meir, I., 2009. A hierarchical, multi-scale, management-responsive model of Mediterranean vegetation dynamics. Ecological Modelling, 220:1148-1158.

Laio, F., Porporato, A., Ridolfi, L. and Rodriguez-Iturbe, I., 2001. Plants in water-controlled ecosystems: active role in hydrologic processes and response to water stress - II. Probabilistic soil moisture dynamics. Advances in Water Resources, 24:707-723.

Letai, J. and Lind, J., 2013. Squeezed from all sides: changing resource tenure and pastoralist innovation on the Laikipia Plateau, Kenya. In: A. Catley, J. Lind and I. Scoones (Editor), Pastoralism and Development in Africa: Dynamic Change at the Margins. Routledge, New York, pp. 164-176.

Lohmann, D., Tietjen, B., Blaum, N., Joubert, D.F. and Jeltsch, F., 2012. Shifting thresholds and changing degradation patterns: climate change effects on the simulated long-term response of a semi-arid savanna to grazing. Journal of Applied Ecology, 49:814-823. 
Ludwig, J.A., Wilcox, B.P., Breshears, D.D., Tongway, D.J. and Imeson, A.C., 2005. Vegetation patches and runoff-erosion as interacting ecohydrological processes in semiarid landscapes. Ecology, 86:288-297.

Meron, E., 2012. Pattern-formation approach to modelling spatially extended ecosystems. Ecological Modelling, 234:70-82.

Miehe, S., Kluge, J., Von Wehrden, H. and Retzer, V., 2010. Long-term degradation of Sahelian rangeland detected by 27 years of field study in Senegal. Journal of Applied Ecology, 47:692-700.

Millennium Ecosystem Assessment, 2005. Dryland systems. In: R. Hassan, R. Scholes and N. Ash (Editor), Ecosystems and human well-being: current state and trends: findings of the Condition and Trends Working Group. Island Press, Washington DC, pp. 623-660.

Monger, C., Sala, O.E., Duniway, M.C., Goldfus, H., Meir, I.A., Poch, R.M., Throop, H.L. and Vivoni, E.R., 2015. Legacy effects in linked ecological-soil-geomorphic systems of drylands. Frontiers in Ecology and the Environment, 13:13-19.

Oba, G., 2012. Harnessing pastoralists' indigenous knowledge for rangeland management: three African case studies. Pastoralism, 2:1-25.

Orlowsky, B. and Seneviratne, S.I., 2013. Elusive drought: uncertainty in observed trends and short- and long-term CMIP5 projections. Hydrology and Earth System Sciences, 17:1765-1781.

Otieno, D.O., Schmidt, M.W.T., Kinyamario, J.I. and Tenhunen, J., 2005. Responses of Acacia tortilis and Acacia xanthophloea to seasonal changes in soil water availability in the savanna region of Kenya. Journal of Arid Environments, 62:377-400. 
Perera, A., Drew, C.A. and Johnson, C., 2012. Experts, Expert Knowledge, and Their Roles in Landscape Ecological Applications. In: A.H. Perera, C.A. Drew and C.J. Johnson (Editor), Expert Knowledge and Its Application in Landscape Ecology. Springer New York, pp. 1-10.

Perry, G.L. and Enright, N.J., 2006. Spatial modelling of vegetation change in dynamic landscapes: a review of methods and applications. Progress in Physical Geography, $30: 47-72$.

Reid, R.S., Fernández-Giménez, M.E. and Galvin, K.A., 2014. Dynamics and Resilience of Rangelands and Pastoral Peoples Around the Globe. Annual Review of Environment and Resources, 39:217-242.

Reynolds, J.F., Stafford Smith, D.M., Lambin, E.F., Turner, B.L., Mortimore, M., Batterbury, S.P.J., Downing, T.E., Dowlatabadi, H., Fernandez, R.J., Herrick, J.E., Huber-Sannwald, E., Jiang, H., Leemans, R., Lynam, T., Maestre, F.T., Ayarza, M. and Walker, B., 2007. Global desertification: Building a science for dryland development. Science, 316:847851.

Rietkerk, M., Boerlijst, M.C., van Langevelde, F., HilleRisLambers, R., van de Koppel, J., Kumar, L., Prins, H.H.T. and de Roos, A.M., 2002. Self-organization of vegetation in arid ecosystems. American Naturalist, 160:524-530.

Rietkerk, M., Dekker, S.C., de Ruiter, P.C. and van de Koppel, J., 2004. Self-organized patchiness and catastrophic shifts in ecosystems. Science, 305:1926-1929. 
Rietkerk, M., Ketner, P., Burger, J., Hoorens, B. and Olff, H., 2000. Multiscale soil and vegetation patchiness along a gradient of herbivore impact in a semi-arid grazing system in West Africa. Plant Ecology, 148:207-224.

Rietkerk, M., Ketner, P. and Stroosnijder, L., 1996. Sahelian rangeland development; a catastrophe? Journal of Range Management, 49:512-519.

Rietkerk, M. and van de Koppel, J., 1997. Alternate stable states and threshold effects in semiarid grazing systems. Oikos, 79:69-79.

Rietkerk, M. and Van de Koppel, J., 2008. Regular pattern formation in real ecosystems. Trends in Ecology \& Evolution, 23:169-175.

Rodriguez-Itubre, R.I. and Porporato, A., 2004. Ecohydrology of Water-Controlled Ecosystems. Cambridge University Press, Cambridge, UK.

Ruppert, J.C., Harmoney, K., Henkin, Z., Snyman, H.A., Sternberg, M., Willms, W. and Linstädter, A., 2015. Quantifying drylands' drought resistance and recovery: the importance of drought intensity, dominant life history and grazing regime. Global change biology, 21:1258-1270.

Saco, P., Willgoose, G. and Hancock, G., 2006. Eco-geomorphology and vegetation patterns in arid and semi-arid regions. Hydrology and Earth System Sciences Discussions, 3:25592593.

Sala, O.E., Gherardi, L.A., Reichmann, L., Jobbágy, E. and Peters, D., 2012. Legacies of precipitation fluctuations on primary production: theory and data synthesis. Philosophical Transactions of the Royal Society B: Biological Sciences, 367:3135-3144. 
Scanlon, T.M., Caylor, K.K., Levin, S.A. and Rodriguez-Iturbe, I., 2007. Positive feedbacks promote power-law clustering of Kalahari vegetation. Nature, 449:209-U204.

Scheffer, M., Carpenter, S., Foley, J.A., Folke, C. and Walker, B., 2001. Catastrophic shifts in ecosystems. Nature, 413:591-596.

Schwinning, S., Sala, O.E., Loik, M.E. and Ehleringer, J.R., 2004. Thresholds, memory, and seasonality: understanding pulse dynamics in arid/semi-arid ecosystems. Oecologia, 141:191-193.

Stewart, J., Parsons, A., Wainwright, J., Okin, G., Bestelmeyer, B., Fredrickson, E. and Schlesinger, W., 2014. Modeling emergent patterns of dynamic desert ecosystems. Ecological Monographs, 84:373-410.

Tietjen, B. and Jeltsch, F., 2007. Semi-arid grazing systems and climate change: a survey of present modelling potential and future needs. Journal of Applied Ecology, 44:425-434.

Tietjen, B., Jeltsch, F., Zehe, E., Classen, N., Groengroeft, A., Schiffers, K. and Oldeland, J., 2010. Effects of climate change on the coupled dynamics of water and vegetation in drylands. Ecohydrology, 3:226-237.

Tietjen, B., Zehe, E. and Jeltsch, F., 2009. Simulating plant water availability in dry lands under climate change: A generic model of two soil layers. Water Resources Research, 45:-.

Tongway, D. and Hindley, N., 2004. Landscape function analysis: a system for monitoring rangeland function. African Journal of Range \& Forage Science, 21:109-113.

Tongway, D.J. and Ludwig, J.A., 2011. Chapter 13: Landscape Function Analysis: An Overview and Landscape Organization Indicatorss. In: D.J. Tongway and J.A. Ludwig (Editor), 
Restoring Disturbed Landscapes: putting principles into practice. Island Press, Washington, DC, pp. 139-144.

Turnbull, L., Wainwright, J. and Brazier, R.E., 2008. A conceptual framework for understanding semi-arid land degradation: ecohydrological interactions across multiple-space and time scales. Ecohydrology, 1:23-34.

Turnbull, L., Wilcox, B.P., Belnap, J., Ravi, S., D'Odorico, P., Childers, D., Gwenzi, W., Okin, G., Wainwright, J., Caylor, K. and Sankey, T., 2012. Understanding the role of ecohydrological feedbacks in ecosystem state change in drylands. Ecohydrology, 5:174183.

van de Koppel, J., Rietkerk, M., van Langevelde, F., Kumar, L., Klausmeier, C.A., Fryxell, J.M., Hearne, J.W., van Andel, J., de Ridder, N., Skidmore, A., Stroosnijder, L. and Prins, H.H.T., 2002. Spatial heterogeneity and irreversible vegetation change in semiarid grazing systems. American Naturalist, 159:209-218.

Weber, G.E., Moloney, K. and Jeltsch, F., 2000. Simulated long-term vegetation response to alternative stocking strategies in savanna rangelands. Plant Ecology, 150:77-96.

Wendt, D.E. and Starr, R.M., 2009. Collaborative Research: An Effective Way to Collect Data for Stock Assessments and Evaluate Marine Protected Areas in California. Marine and Coastal Fisheries, 1:315-324.

Wiegand, T., Jeltsch, F., Hanski, I. and Grimm, V., 2003. Using pattern-oriented modeling for revealing hidden information: a key for reconciling ecological theory and application. Oikos, 100:209-222. 
Wilcox, B.P. and Newman, B.D., 2005. Ecohydrology of semiarid landscapes. Ecology, 86:275276. 


\section{Appendix A: Summary of MVUACHACHE Model Using Updated ODD (Overview, Design Concepts, Details) Protocol (from Grimm et al., 2010)}

\section{Purpose}

The model was designed to simulate spatial and temporal patterns of vegetation change on a hillslope in a semi-arid rangeland, in response to simulated stochastic rainfall and user-defined levels of surface runoff channelization, tree root-to-crown radius ratio, and grazing intensity. The model achieves this purpose by (a) simulating the biophysical water-soil-plant interactions that govern soil moisture during a growing season, (b) ascribing probabilistic transitions between bare, annual grass, and perennial grass states in each patch, based on average growing season soil moisture, and (c) ascribing dry-season survival probabilities to annual and perennial grass patches, which depend on an index value of grazing intensity.

\section{Entities, state variables, and scales}

\subsection{Entities:}

The agent entities in the model are patches, which are $2 \times 2 \mathrm{~m}$ grid cells, in a horizontallywrapping domain (i.e. periodic boundary condition) of 100x100 cells that represents a hillslope.

The environment in the model is governed by daily rainfall, which affects all grid cells and generated through a stochastic daily timestep simulation as described in Section 6. 


\subsection{State variables:}

Patches exist as one of 5 possible types: annual grass $(A)$, perennial grass $(P)$, bare soil $(B)$, degraded bare soil $(B B)$, and tree $(T)$.

\subsubsection{Hydrological submodel variables:}

Each type has characteristic soil and vegetation parameters that are used in the hydrological submodel to calculate soil moisture at each daily timestep for each patch, as described in detail in Section 7, and do not vary with time during the simulation. These parameters are presented in Table A.1.

Table A.1: Parameter names, symbols, units, and patch-specific values used in the hydrological submodel of MVUACHACHE. Values in plain type are from Table 2 and Table 5 of (Franz et al. 2012). Values in bold type are updated or new for MVUACHACHE. Values reported in parentheses are SE.

\begin{tabular}{|c|c|c|c|c|c|}
\hline Parameter, symbol (units) & $\begin{array}{l}\text { Annual } \\
\text { Grass }\end{array}$ & $\begin{array}{c}\text { Perennial } \\
\text { Grass }\end{array}$ & Bare & $\begin{array}{c}\text { Degraded } \\
\text { Bare }\end{array}$ & Tree \\
\hline Soil depth, $Z_{r}(\mathrm{~mm})^{\mathrm{a}}$ & 400 & 400 & 400 & 400 & 400 \\
\hline $\begin{array}{l}\text { Maximum canopy interception, } I_{\max } \\
(\mathrm{mm})^{\mathrm{a}}\end{array}$ & 1 & 1 & 0 & 0 & 2 \\
\hline $\begin{array}{l}\text { Maximum evapotranspiration, } E_{\max } \\
\left(\mathrm{mm} \mathrm{d}^{-1}\right)^{\mathrm{b}}\end{array}$ & 4 & 4 & 7 & 7 & 6 \\
\hline
\end{tabular}




\begin{tabular}{|c|c|c|c|c|c|}
\hline $\begin{array}{l}\text { Vertical saturated hydraulic } \\
\text { conductivity } K_{s v}\left(\mathrm{~mm} \mathrm{~h}^{-1}\right)^{\mathrm{c}}\end{array}$ & $\begin{array}{l}16.7 \\
(1.53)\end{array}$ & $\begin{array}{l}16.7 \\
(1.53)\end{array}$ & $\begin{array}{c}6.6 \\
(0.779)\end{array}$ & $4.62^{\mathrm{d}}$ & $\begin{array}{l}14.5 \\
(2.31)\end{array}$ \\
\hline $\begin{array}{l}\text { Incipient Hortonian Runoff } \\
\text { generation, } R_{d}^{*}(\mathrm{~mm})^{\mathrm{e}}\end{array}$ & 6 & 6 & 6 & 6 & 6 \\
\hline Porosity, $n\left(\mathrm{~m}^{3} \mathrm{~m}^{-3}\right)^{\mathrm{f}}$ & 0.45 & 0.45 & 0.45 & 0.45 & 0.45 \\
\hline Air entry pressure, $\psi_{a e}(\mathrm{~cm})^{\mathrm{f}}$ & 21.8 & 21.8 & 21.8 & 21.8 & 21.8 \\
\hline Pore size index, $b(-)^{\mathrm{f}}$ & 4.9 & 4.9 & 4.9 & 4.9 & 4.9 \\
\hline $\begin{array}{l}\text { Soil water retention curve, } \psi_{a v g} \\
(\mathrm{MPa})^{\mathrm{g}}\end{array}$ & -0.0007 & -0.0007 & -0.0007 & -0.0007 & -0.0007 \\
\hline $\begin{array}{l}\text { Hygroscopic saturation, } s_{h}(\% \text {, where } \\
\psi=-10 \mathrm{MPa})^{\mathrm{g}}\end{array}$ & 0.1419 & 0.1419 & 0.1419 & 0.1419 & 0.1419 \\
\hline $\begin{array}{l}\text { Field capacity saturation, } s_{f c}(\% \text {, where } \\
\psi=-0.033 \mathrm{MPa})^{\mathrm{g}}\end{array}$ & 0.4555 & 0.4555 & 0.4555 & 0.4555 & 0.4555 \\
\hline $\begin{array}{l}\text { Soil matric potential at wilting point, } \\
\psi_{\text {wilt }}(\mathrm{MPa})^{\mathrm{h}, \mathrm{i}}\end{array}$ & $-2.4^{i}$ & $-3^{\mathrm{h}}$ & NA & NA & $-3^{\mathrm{h}}$ \\
\hline Wilting point saturation, $s_{w}(\%)^{\mathrm{j}}$ & 0.1899 & 0.1815 & NA & NA & 0.1815 \\
\hline $\begin{array}{l}\text { Soil matric potential at incipient } \\
\text { stomatal closure, } \psi *(\mathrm{MPa})^{\mathrm{h}, \mathrm{k}}\end{array}$ & $-0.0405^{\mathrm{k}}$ & $-0.045^{\mathrm{h}}$ & NA & NA & $-0.045^{\mathrm{h}}$ \\
\hline $\begin{array}{l}\text { Incipient stomatal closure point } \\
\text { saturation, } s *(\%)^{\mathrm{j}}\end{array}$ & 0.4369 & 0.4276 & NA & NA & 0.4276 \\
\hline Water stress exponent ${ }^{g}$ & 2 & 2 & NA & NA & 2 \\
\hline Evaporation exponential decay & 0.0305 & 0.0305 & 0.0621 & 0.0621 & 0.0565 \\
\hline
\end{tabular}




\begin{tabular}{|c|c|c|c|c|c|}
\hline constant, $k\left(\mathrm{~m}^{3} / \mathrm{m}^{3} / \text { day }\right)^{1 . \mathrm{m}}$ & $(0.0038)^{1}$ & $(0.0038)^{1}$ & $(0.0041)^{1}$ & $(0.0041)^{1}$ & $(0.0056)^{\mathrm{m}}$ \\
\hline $\begin{array}{l}\text { Mean daily patch water use at well } \\
\text { watered conditions }=n^{*} Z_{r}{ }^{*} k^{*} s_{f c} \\
(\mathrm{~mm} / \text { day) }\end{array}$ & 2.5 & 2.5 & 5.09 & 5.09 & 4.63 \\
\hline \multicolumn{6}{|l|}{ Runoff $\left(R_{d}\right)$ model coefficients ${ }^{\mathrm{n}, \mathrm{o}, \mathrm{p}}$} \\
\hline $\mathrm{C}_{0}^{\mathrm{R}_{0}}$ & $-3.389^{\circ}$ & $-3.389^{n}$ & $-2.324^{n}$ & $-3.17 p$ & $-2.630^{n}$ \\
\hline $\mathrm{C}_{1}^{\mathrm{R}}$ & $1.4489^{\circ}$ & $1.4489^{n}$ & $1.519^{\mathrm{n}}$ & $2.093{ }^{p}$ & $1.43393^{n}$ \\
\hline $\mathrm{C}_{2}^{\mathrm{R}}$ & $0.7687^{\circ}$ & $0.7687^{n}$ & $0.4975^{\mathrm{n}}$ & $0.1766^{p}$ & $0.3621^{\mathrm{n}}$ \\
\hline $\mathrm{C}_{3}^{\mathrm{R}_{3}}$ & $1.401^{\mathrm{o}}$ & $1.401^{\mathrm{n}}$ & $1.250^{\mathrm{n}}$ & $1.159 \mathrm{p}$ & $1.281^{\mathrm{n}}$ \\
\hline Regression model $\mathrm{R}_{\text {adj }}^{2}$ & $0.90^{\circ}$ & $0.90^{\mathrm{n}}$ & $0.92^{\mathrm{n}}$ & $0.95^{p}$ & $0.88^{\mathrm{n}}$ \\
\hline
\end{tabular}

${ }^{\text {a }}$ Assumed value

${ }^{\mathrm{b}}$ Approximated by Penman-Monteith, Penman-Combination equation, using growing season climate parameters

(Table A.2) and vegetation characteristics (Franz et al., 2010). Value in parenthesis is standard error of mean.

${ }^{\mathrm{c}}$ Estimated from 12 samples in each patch type collected with minidisc infiltrometer in July 2007 (Franz et al., 2012).

d Assumed value, $70 \%$ of $B$.

${ }^{\mathrm{e}}$ Estimated from 21 storm events for $4 \times 4$ m runoff plots during 2 year experiment (Franz et al., 2012).

${ }^{\mathrm{f}}$ Estimated from sandy loam (Clapp and Hornberger, 1978; Dingman, 2002) based on 30 texture samples from study site.

g Adopted from (Rodriguez-Iturbe and Porporato, 2004).

${ }^{\text {h }}$ Estimated from (Otieno et al., 2005) and (Laio et al., 2001).

${ }^{\text {i }}$ Value for $A$ patches assumed to be $80 \%$ of $P$ and $T$ patch value.

${ }^{\mathrm{j}}$ The values of $s_{w}$ and $s_{*}$ are derived from the corresponding values of soil matric potential, $\psi_{w}$ and $\psi^{*}$, respectively, using soil-type specific soil-moisture retention curves (Clapp and Hornberger, 1978).

${ }^{k}$ Value for $A$ patches assumed to be $90 \%$ of $P$ and $T$ patch value. 


\footnotetext{
${ }^{1}$ Estimated from 15 inter-storm periods during 2 year experiment. Value in parenthesis is standard error of mean.

${ }^{\mathrm{m}}$ Value is for combined grass and tree patch. Subtract grass decay constant from this value to obtain tree only decay constant for roots that extend beyond canopy crown.

${ }^{\mathrm{n}}$ Estimated from 21 storm events over a 2 year period using stepwise multivariate linear regression.

${ }^{\circ}$ Assumed the same as $P$.

${ }^{\mathrm{p}}$ Assumed runoff depth increased by $20 \%$ from 21 storm events of $B$. Coefficients then recomputed using multivariate linear regression.
}

\section{Process overview and scheduling}

The general workflow of the model is summarized in Figure 2. In each growing season daily time step the Soil Moisture Dynamics of each grid cell are calculated based off of direct precipitation to the grid plus and additional runon from Surface Flowpath Convergence. The Daily Water Stress is then computed for each vegetated grid cell. After the growing season the soil moisture availability quantile and stress avoidance quantile are computed for each grid cell (Figure 4 gives GEV fits for each grid cell patch type). The resulting quantiles are then used to update the grid cell patch state (Figure 3 describes possible patch changes and Figure 5 illustrates the matrix of transition probabilities) for the start of the next dry season. Using the stress avoidance quantile and grazing intensity quantile, the vegetated patch grid cells are updated (Figures 3 and 6) for the start of the next growing season.

\section{Design concepts}

\subsection{Basic principles}


This model extends an earlier growing season cellular automata model simulating hillslope scale daily soil moisture dynamics. The underlying principles derive from hydrogeophysical and ecohydrological understanding of horizontal and vertical water redistribution and plant water uptake in drylands. The MVUACHACHE model additionally includes transient seasonal dynamics of the herbaceous layer based on probabilistic patch state transitions. At the end of the growing season, transition probabilities are continuous functions of average growing season soil moisture availability and plant water stress, thereby phenomenologically representing the ecological principles of plant responses to abiotic stress. At the end of the dry season, the probability of $A$ and $P$ patch persistence is governed not only by grazing intensity, but also antecedent growing season plant water stress. These transition functions serve to integrate several ecological processes (such as growth, reproduction, and carbohydrate storage) that may allow grass patches to better withstand (perennials) or reseed after (annuals) heavy grazing, if they enjoyed greater soil moisture availability during the growing season.

\subsection{Emergence}

The abundance and spatial organization of herbaceous vegetation emerge from interactions with soil moisture availability, plant water stress, and grazing intensity.

\subsection{Adaptation:}

Agents change their patch type in response to growing-season average soil moisture and plant water stress avoidance, and vegetated patches change their state in response to grazing intensity. However the changes are not considered adaptive since they are not linked to objectives or fitness maximization. 


\subsection{Objectives:}

Agent responses do not represent decisions to attain objectives.

\subsection{Learning and Prediction:}

Agents utilize the same patch transition probabilities throughout the simulation, therefore no learning or prediction is incorporated.

\subsection{Sensing and interaction}

Colonization and dieoff of grid cells by agents are influenced by the local neighborhood (i.e. 8 first level neighbors). Clustering of vegetated grid cells is more effective at trapping surface runoff, thus decreasing overall plant water stress and increasing chances for colonization. In addition, roots from tree grid cells can remove water from local neighborhood thus creating feedback between the benefits of being near a runoff capturing tree grid cell and competition for soil water by overlapping root canopies. The system is strongly influenced by Hortonian runoff dynamics, so flow of water through the domain creates connectivity between cells. Cells "sense" the calculated seasonal average soil moisture availability and grazing intensity, then respond according to probabilistic transition functions.

\subsection{Stochasticity:}

Growing season rainfall is modelled as a Marked Poisson point process. The mean daily rainfall depth and arrival rate of storms are modelled as exponential distributions characterized by only their mean. The initial distribution of grid cell patch type is generated by a Neyman-Scott 
Process characterized by the mean distance between cluster sites and mean distance of children from parent cluster sites (Franz et al., 2012). The growing and dry season grid cell patch updates are governed by soil moisture availability, plant water stress, and grazing intensity quantiles, which are combined in probabilistic transition functions. Transitions are determined by generating a random number from a uniform distribution for each grid cell and for each season (Figures 2, 4, 5).

\subsection{Collectives:}

Cells can influence soil moisture in neighboring cells, but there are no collectives. Cells respond autonomously to hydrological and grazing conditions.

\subsection{Observation:}

At each daily timestep, soil moisture data is collected for each agent in the simulation. At the end of the growing season and at the end of the dry season, the seasonal daily soil moisture is averaged, and from it is calculated a quantile value for average daily soil moisture (in $B$ and $B B$ patches) or average daily stress avoidance (for $A$ and $P$ patches). At the end of each growing season and dry season, data on patch type is collected for each agent in the domain. From these data, the percentage of cover of each patch type is be calculated for the domain. Also, the size and shape of vegetation clusters and bare areas can be calculated from these data.

\section{Initialization}

The initial distribution of grid cell patch type is generated by a Neyman-Scott Process characterized by the mean distance between cluster sites and mean distance of children from 
parent cluster sites (Franz et al. 2012). The user selects the initial fractional cover of each patch type (making sure the sum of fractions is 1 !) and the two mean distances needed for the NeymanScott Process (i.e. each mean distance is simulated with an exponential distribution). For relatively large mean distances (i.e. compared to the domain size) the Neyman-Scott Process approaches a random distribution. A grid cell location and type is then randomly chosen until the overall fractional cover approaches the initial fractional covers chosen by the user. For the Neyman-Scott Process used here, $T$ patches are first generated in a $B$ matrix domain to its user defined fractional cover and mean distances. Next, $A, P$, and $B B$ are placed randomly in the $B / T$ domain until reaching the user defined fractional covers. The initial soil moisture value for each patch was set to the incipient stomata closure saturation (Table A.1), which is the point at which stress begins and we assumed the start of significant response in the vegetation to additional rainfall. Franz et al. (2012) note that starting initial soil moisture did not affect the relative growing season water balances.

\section{Input data}

\subsection{Rainfall simulation}

Daily rainfall, $P(x, t)$, is characterized as a marked Poisson process with an interstorm arrival rate $\left(\right.$ day $\left.^{-1}\right)$ of $\lambda$ and a storm depth (mm) of $\alpha$. The rainfall process is further characterized by a daily rainfall intensity, $i\left(\mathrm{~mm} \mathrm{hr}^{-1}\right)$, which is assumed to be independent of storm depth. The underlying probability distributions of interstorm arrival rate, rainfall depth, and rainfall intensity are all taken to be exponential, with mean values of each distribution derived from observations of the rainfall process within the study basin (Table A.2). Note that mean growing season 
precipitation $\left(\mu=\alpha \lambda T_{\text {seas }}\right)$ and the variance of growing season precipitation $\left(\sigma^{2}=2 \alpha^{2} \lambda T_{\text {seas }}\right)$ can be computed from the rainfall characteristics and growing season length ( $T_{\text {seas }}$, day). Using the mean storm depth, interstorm arrival rate and growing season length, the user can simulate the desired number of growing seasons to simulate. Finally, the remaining atmospheric forcing data in Table A.2 was used to calculate potential evapotranspiration rates.

Table A.2 Growing season climate parameters for field site in Kenya

\begin{tabular}{lc}
\hline \hline Length of growing season (day) $^{\mathrm{a}}$ & 90
\end{tabular}

Number of growing seasons per year ${ }^{\mathrm{a}}$

Total rainfall $(\mathrm{mm})^{\mathrm{b}}$

Coefficient of variation ${ }^{b}$

0.318

Percent of annual rainfall per growing season ${ }^{\mathrm{b}}$

Mean daily storm depth, $\alpha(\mathrm{mm})^{\mathrm{b}}$

9

Mean storm arrival rate, $\lambda\left(\text { day }^{-1}\right)^{\mathrm{b}}$

Average rainfall rate, $i\left(\mathrm{~mm} \mathrm{hr}^{-1}\right)^{\mathrm{c}}$

Mean daily relative humidity $(\%)^{\mathrm{d}}$

Mean daily pan evaporation $\left(\mathrm{mm} \mathrm{day}^{-1}\right)^{\mathrm{d}}$

Mean daily incoming shortwave radiation $\left(\mathrm{W} \mathrm{m}^{-2} \text { daylight }^{-1}\right)^{\mathrm{d}}$ 325(90)

Mean sunshine hours (hrs day $\left.{ }^{-1}\right)^{\mathrm{d}}$

Mean daily temperature $\left({ }^{\circ} \mathrm{C}\right)^{\mathrm{d}}$

Mean daily wind speed $\left(\mathrm{m} \mathrm{s}^{-1}\right)^{\mathrm{d}}$

aprimary growing seasons are March to May and October to December.

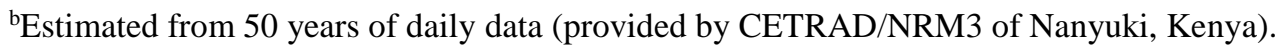


${ }^{\mathrm{c}}$ Estimated from 21 storm events over 2 year experiment measured with tipping bucket rain gage (10 minute intervals).

${ }^{\text {d}}$ Estimated from 15 years of daily data (provided by CETRAD/NRM3 of Nanyuki, Kenya).

Note: Values reported in parentheses are standard deviations.

\section{Details of the hydrological submodel of the MVUACHACHE model}

The hydrological submodel is described for $B, P$, and $T$ patches in (Franz et al., 2012). Here we present a general overview of the governing equations and processes used to model (A) soil moisture dynamics, (B) the horizontal surface water flow with varying degrees of flowpath convergence, and (C) daily water stress. Soil and vegetation parameter values used can be found in Table 2 of (Franz et al. 2012). Parameter values for $A$ patches are identical to those for $P$ patches, and $B B$ patches are identical to $B$ patches, except where noted below and shown in Table A.1.

\subsection{Soil moisture dynamics}

The governing equation for the root-zone daily soil moisture in each patch $x$ at time $t$ is

$Z_{r} \frac{\Delta \theta(t)}{\Delta t}=I(x, t)-L(x, t)-E T(x, t)$

where $Z_{r}$ is the effective root depth $(\mathrm{mm}), \theta$ is the root-zone soil moisture $\left(\mathrm{m}^{3} \mathrm{~m}^{-3}\right), I$ is the daily infiltration rate of water inputs into the root zone, $L$ is the daily vertical leakage rate, and $E T$ and 
the daily evapotranspiration rate (all in $\mathrm{mm} \mathrm{day}^{-1}$ ). Infiltration rate was calculated as a function of daily effective rainfall $P_{e}$, soil physical characteristics, and soil saturation, $s(\%)$, which is related to soil moisture, $\theta$, by $s=\frac{\theta}{n}$, where $n$ is the soil porosity $\left(\mathrm{m}^{3} \mathrm{~m}^{-3}\right)$.

The daily water balance was separated into regimes for rainy days and dry days. On days without rainfall, soil moisture change is driven by $E T$, and the soil moisture solution follows an exponential decay which asymptotically approaches an assumed hygroscopic saturation point, $s h$ (Rodriguez-Itubre and Porporato, 2004). We used empirically-estimated patch-specific decay constants $k\left(\mathrm{~m}^{3} \mathrm{~m}^{-3} \mathrm{~d}^{-1}\right)$ derived at the field site (Franz et al., 2012). Each patch was assigned an effective $k$ value in order to include the influence of tree roots from neighboring cells, as determined by the root to canopy radius parameter $R C R$, such that effective $k$ is the sum of fraction of roots multiplied by the patch type decay constant for the contributing neighbors.

On rainy days, we make the simplifying assumption that evapotranspiration is zero, leaving rainfall inputs and leakage as affecting root zone soil moisture. $P_{e}(t)$ is the sum of direct daily rainfall $P(t)$ and runoff from upslope patches $R_{u}(t)$, so that

$P_{e}(t)=P(t)+R_{u}(t)$

The calculation of $R_{u}(t)$ is addressed in Section 7.2 of this appendix. Daily rainfall, $P(t)$, is characterized as a marked Poisson process with an interstorm arrival rate $\left(\right.$ day $\left.^{-1}\right)$ of $\lambda$, a storm depth of $\alpha(\mathrm{mm})$, and a daily average rainfall intensity, $i\left(\mathrm{~mm} \mathrm{hr}^{-1}\right)$, which is assumed to be independent of storm depth. The underlying probability distributions of $\lambda, \alpha$, and $i$ are all taken 
to be exponential, with mean values of each distribution derived from observations of the rainfall patterns within the study basin.

The model assumes a threshold storm depth, $\Delta(\mathrm{mm})$, below which no water penetrates a vegetated patch canopy, and includes a maximum canopy interception value, $I_{\max }(\mathrm{mm})$, and an incipient Hortonian runoff threshold, $R_{d}^{*}(\mathrm{~mm})$, that must be exceeded in order for vegetated patches to generate surface runoff, $R_{d}$. When the effective precipitation depth exceeds the incipient runoff threshold, infiltration may then increase soil moisture. If effective precipitation depth exceeds the storage capacity of the soil, saturation runoff contributes to $R_{d}$.

The downslope runoff $\left(R_{d}\right)$ generated in each patch is estimated using an equation obtained from an empirical multiple least squares regression of daily rainfall $P_{e}(\mathrm{~mm})$ and intensity $i\left(\mathrm{~mm} \mathrm{~h}^{-1}\right)$ on daily total runoff (mm), which was measured over 2 years on $4 \mathrm{x} 4 \mathrm{~m} B, P$, and $T$ patches with installed gutters, rails, and runoff collecting tanks (Franz et al., 2012). The relationship took the form of a general exponential model

$R_{d}\left(P_{e}, i\right)=\left[C_{0}^{R}+C_{1}^{R} \ln \left(P_{e}\right)+C_{2}^{R} \ln (i)+C_{3}^{R}\left(\left(\ln \left(P_{e}\right)-2.4449\right) \times(\ln (i)-1.6661)\right)\right]^{2}$

where $C_{o}^{R}$ to $C_{3}^{R}$ were coefficients from the regression models for each patch type. We lacked empirically derived coefficients for $B B$ and $A$ patches to use in the hydrological submodel in MVUACHACHE. To estimate them, we assumed that $A$ patches would have the same runoff as $P$ patches, and that $B B$ patches would have $20 \%$ more runoff than $B$ patches, which yielded the runoff coefficients shown in Table A.1 
Soil water can be lost through vertical leakage $(L)$ if the depth of the infiltration front exceeds the soil rooting depth, and is represented by

$L[s(t)]=\frac{K_{S}}{e^{\beta\left(1-s_{f c}\right)_{-1}}}\left[e^{\beta\left(1-s_{f c}\right)}-1\right]$

where $K_{s}$ is the vertical saturated hydraulic conductivity $\left(\mathrm{mm} \mathrm{day}^{-1}\right), s_{f c}$ is the soil field capacity (dimensionless), and $\beta=2 b+4$, where $b$ is the pore size distribution index (dimensionless) (Clapp and Hornberger, 1978).

\subsection{Surface flowpath convergence}

Runoff can enter each patch $x$ from its three neighboring upslope patches $j$, according to

$R_{u}(x, t)=\sum_{j=1}^{3}\left(R_{d}(j, t) \times f_{d}(j)\right)$

where $R_{d}(j, t)\left(\mathrm{mm} \mathrm{d}^{-1}\right)$ is the downslope runoff from upslope patch $j$ at time $t$, and $f_{d}(j)$ is the portion of runoff from patch $j$ that enters the downslope patch $x$. Our field observations indicated frequent raised topography in vegetation patches, due to soil erosion in bare areas around vegetation patches and increased deposition of erosion sediments within vegetated patches. This localized topography now reduces direct downslope flow into vegetated patches. Thus in the model, the fraction of runoff entering a patch $x$ depends on whether the patch is vegetated $(A, P, T)$ or bare $(B, B B)$; The parameter $f r$ controls the level of convergence of surface 
flow paths in connected bare patches, and thus controls the fraction of runoff that enters vegetated patches. Values of $f r$ near 0.4 results in flows that are neutral with respect to patch type, whereas values near 0 result in highly convergent flowpaths through connected bare patches. This is done by using the $f r$ parameter to calculate $f_{d}$ coefficients for the three downslope cells, depending on their state as bare $(b)$ or vegetated $(v)$, as follows:

\begin{tabular}{|c|c|c|c|c|}
\hline$b, b, b=v, v, v$ & & $\frac{1}{2(\sqrt{2}+1)}$ & $1-\frac{1}{(\sqrt{2}+1)}$ & $\frac{1}{2(\sqrt{2}+1)}$ \\
\hline$b, v, b$ & & $\frac{1}{2}-\frac{f r}{2}$, & $f r$ & $\frac{1}{2}-\frac{f r}{2}$ \\
\hline$v, b, v$ & & $\frac{f r}{\sqrt{2}}$ & $1-\frac{2 f r}{\sqrt{2}}$ & $\frac{f r}{\sqrt{2}}$ \\
\hline$b, v, v$ & & $1-f r\left(1+\frac{1}{\sqrt{2}}\right)$ & $f r$ & $\frac{f r}{\sqrt{2}}$ \\
\hline$b, b, v$ & & $-\frac{(4 \sqrt{2}+7)(f r-\sqrt{2})}{8 \sqrt{2(\sqrt{2}+1)^{2}}}$ & $-\frac{(f r-\sqrt{2})(17+12 \sqrt{2})}{8 \sqrt{2(\sqrt{2}+1)^{2}}}$ & $\frac{f r}{\sqrt{2}}$ \\
\hline
\end{tabular}

\subsection{Daily water stress}

The steady-state probability distribution of soil moisture over the growing season was determined following (Laio et al., 2001). The normalized daily water stress, $\xi(t)$, was calculated following (Rodriguez-Itubre and Porporato, 2004) as

$\xi(t)=\left\{\begin{array}{cc}0 & s_{*} \leq s(t) \\ {\left[\frac{s_{*}-s(t)}{s_{*}-s_{w}}\right]^{q}} & s_{w}<s(t)<s_{*} \\ 1 & s(t) \leq s_{w}\end{array}\right.$ 
where $s(t)$ is the daily average saturation, $s_{w}$ is the wilting point saturation, $s *$ is the saturation at incipient stomatal closure, and $q$ is the exponent of the saturation stress equation, assumed to be equal to 2 (Rodriguez-Itubre and Porporato, 2004). Water stress avoidance was calculated as $1-\xi(t)$. The seasonal averages of daily soil moisture and daily water stress avoidance were calculated for each patch $x$ and used in the determination of patch type transitions. 


\section{Appendix B: Use of field site transect data in growing-season transition probability calibration.}

In September 2006 and February 2007, we established 24 50m line transects at the study site, oriented in the direction of downslope resource flow, located within $300 \mathrm{~m}$ of the site where water balance parameters were measured, at random starting points that were stratified with respect to hillslope position (upper, mid, lower). We conducted 7 censuses between 2006 and 2013 using the Landscape Function Analysis (LFA) procedure (Tongway and Ludwig, 2011). Due to the research design for other intended uses of the LFA data and logistical constraints, only a subset of the transects had patch monitoring data for consecutive censuses $(t, t+1$; Table B.1). Censuses took place at the peak of the growing season, except for census 1 (Sept. 2006), which took place during the dry season preceding census 2 (February 2007). During each census, we recording the start and end distances (in $\mathrm{cm}$ from start of transect) of patches of different functional cover classes, such that each segment of the line transect was classified as one function cover class. Functional cover classes were based on the presence of at least $10 \%$ cover attributable to grasses $(\mathrm{G})$, forbs $(\mathrm{F})$, shrubs $(\mathrm{S})$, and tree canopy $(\mathrm{T})$, yielding the following classes: G, F, S, T, GF, GS, GT, FS, FT, ST, GFS, GFT, GST, FST, and GFST. Patches with less than $1 \%$ cover were classified as bare (B), while patches with $1 \%<$ cover $<10 \%$ of grass or forbs were classified as bare grass (BG) and bare forb (BF), respectively.

We then re-classified the patches into the model-relevant categories of $b$ (including $\mathrm{B}$, $\mathrm{BG}$, and $\mathrm{BF})$ and $v(=A+P$ in model, and including all other classes without $\mathrm{T})$. This allowed us to examine changes in patch categories on transects that were monitored in consecutive censuses, but they could not be translated directly into transition probabilities for the model, since patches 
varied in size, and any portion of a patch could transition into another cover class. Instead we calculated the proportion of each initial patch with length $>50 \mathrm{~cm}$ at census $t$, that fell into each of the cover classes when remeasured at census $t+1$. For each initial patch type, we averaged the proportions of each possible transition that occurred across all transects to estimate transition frequencies for each patch type, i.e., what was the average proportion of a bare soil patch that remained bare; what was the average proportion that became vegetated, etc. (Table B.1). While this method provides rather coarse estimates, we found it to be the most viable way to infer some idea of transition frequencies given the data we had.

Table B.1 Summary of patch transect data used to calculate the average proportion of individual patches that transitioned or remained the same patch type, from census $t$ to census $t+1$. Patches $<50 \mathrm{~cm}$ long and patches containing trees were excluded.

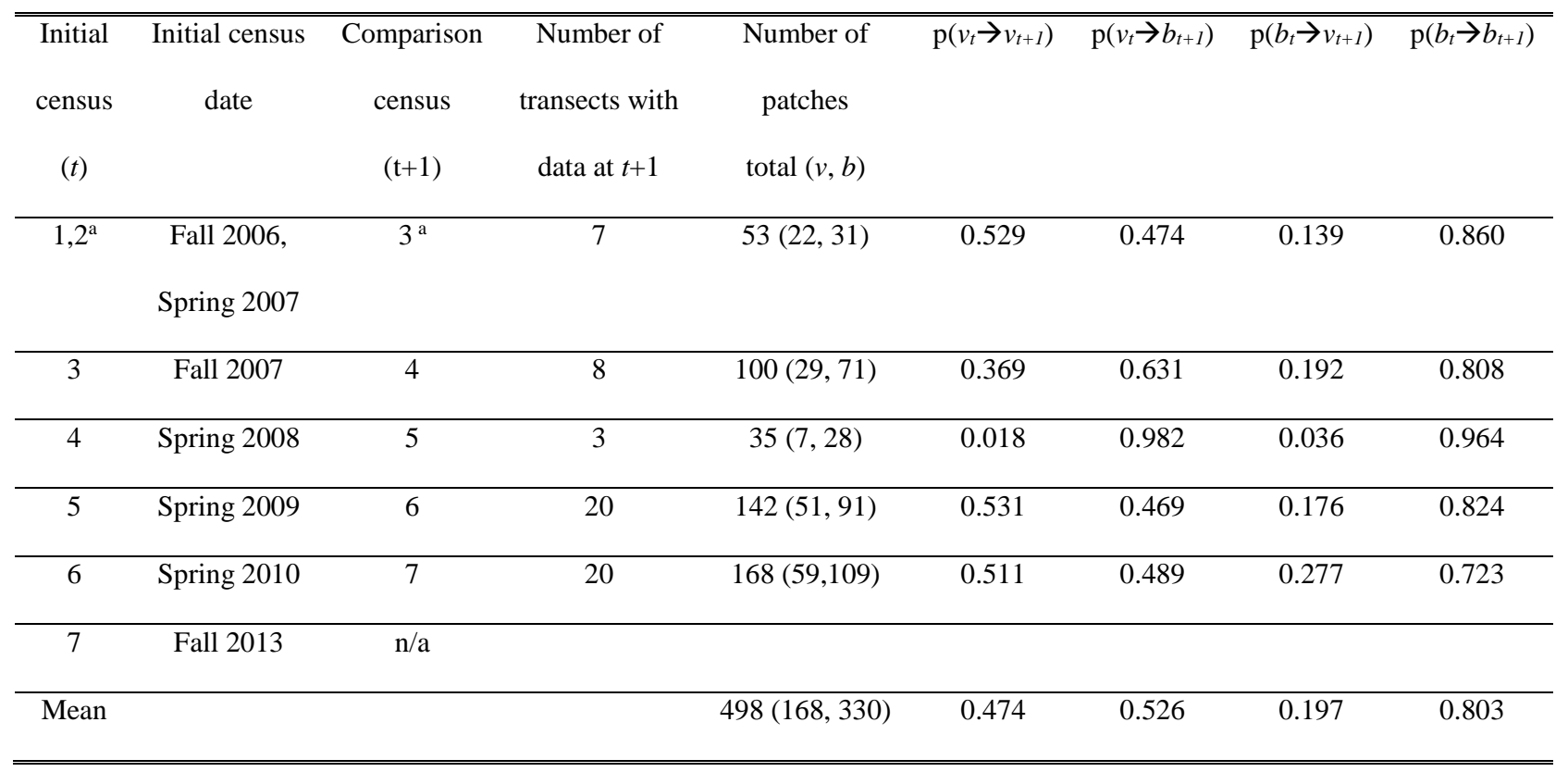


${ }^{a}$ Census 1 took place as the first transects were established during the dry season before census 2. During census 2 , the remainder of transects were established and measured, creating the full set of transects. Transects from census 1 and 2 were both compared to census 3, thus allowing at least a full seasonal cycle between the compared censuses.

The first iterations of estimating growing season patch transitions were based on scientific and local expert opinion, knowledge, and observations, which we used to reason through and make predictions in a planned set of end member scenarios. In using the transect patch changes to further guide the calibration of growing season patch transition probabilities (Figure 5), we first had to consider that all but one comparison spanned more than one growing season and dry season, whereas we sought to estimate transition probabilities for just a single growing season. For instance, when considering the proportion of $b$ patches that transitioned to $\mathrm{v}, \mathrm{p}(b \rightarrow v)$, between censuses, which are reported in Table B. 1 as about $20 \%$ on average over 2 seasons, we considered that within a single season, the proportion would be expected to be approximately half of that.

Second, we also had to consider that looking at the proportions of patch changes did not take into account the per patch cover threshold of $10 \%$ that we assumed to distinguish bare patches in the model. For instance when we considered the average $\mathrm{p}(v \rightarrow b)$ of about $50 \%$ reported in Table B.1, we had to take into account the multiple season rate inflation, but also we examined the distribution of $\mathrm{p}(v \rightarrow b)$ values, and found that of the $100 v$ patches $>2 \mathrm{~m}$ in length, 36 had transitioned to $b$ by $90 \%$ or more. This $36 \%$ provides a complementary estimate of patch transition probability over 2 years that does consider the $10 \%$ cover threshold.

Thirdly, we had to consider that our empirical findings reflect (a) dry season mortality and (b) the impact of year round grazing. The effects of dry season mortality and grazing impacts are modeled separately in MVUACHACHE, and should not influence the growing 
season transitions. The model assumes no impact of grazing on growing season transitions, an assumption that is violated to varying degrees from season to season, depending on socialecological factors such as distant grazing access, local concentrations of livestock, the availability of ephemeral water points, and varying customary grazing regulation at the field site. Despite the many caveats, there was general concordance between the scenario-derived transition matrices and the field data once we allowed for expected biases. 


\section{Appendix C: Five end member rainfall-grazing scenarios used in calibrating dry-season transition probabilities.}

Each scenario prescribes conditions in terms of $Q_{s a}, Q_{s w}, Q_{g i}$, and initial grass cover $(g=A+P)$. Estimated fixed values were proposed for two of the three determinant transition probabilities, while the third probability was a free parameter:

- grass-to-grass transition probability in response to stress avoidance quantile, $\mathrm{p}_{\mathrm{sa}}(g \mid g)$;

- bare-to-grass transition probability in response to soil moisture quantile, $\mathrm{p}_{\mathrm{sm}}(b \mid g)$;

- grass-to-grass transition probability in response to grazing intensity quantile, $\mathrm{p}_{\mathrm{gi}}(g \mid g)$.

For each scenario, we used local herder knowledge and ecological observations to set a target fractional grass cover that would expected under scenario conditions after 3 seasonal cycles. We simulated the scenarios, varying the free parameter from 0 to 1 in steps of 0.005 . We were thereby able to identify the value of the free parameter that would satisfy the expected grass cover after three seasons, as well as visualize the sensitivity of model output to that parameter.

Table C.1: Details of the scenario conditions, fixed probability estimates, and target fractional grass cover expected after three seasons. For each scenario, the free parameter values that best met the expected 3-season model outcome are indicated in bold italics.

Scenario

$\begin{array}{llllll}1 \text { (a) } & 1 \text { (b) } & 2 & 3 & 4 & 5\end{array}$

Scenario conditions 


$\begin{array}{ccccccc}\mathrm{Q}_{\mathrm{sa}} & 0.25 & 0.25 & 0.75 & 0.75 & 0.75 & 0.5 \\ \mathrm{Q}_{\mathrm{sm}} & 0.25 & 0.25 & 0.75 & 0.75 & 0.75 & 0.5 \\ \mathrm{Q}_{\mathrm{gi}} & 0.2 & 0.2 & 0.2 & 0.8 & 0.2 & 0.5\end{array}$

$\begin{array}{lllllll}g \text { initial } & 0.75 & 0.75 & 0.05 & 0.2 & 0.75 & 0.35\end{array}$

Fixed \& free parameters

\begin{tabular}{ccccccc}
$p_{\mathrm{sa}}(g \mid g)$ & 0.99 & 0.9 & 0.99 & 0.99 & 0.99 & 0.99 \\
$\mathrm{p}_{\mathrm{sm}}(b \mid g)$ & $\boldsymbol{n} / \boldsymbol{a}$ & $\mathbf{0 . 0 0 5}$ & $\mathbf{0 . 0 9 5}$ & 0.095 & 0.095 & 0.05 \\
$\mathrm{p}_{\mathrm{gi}}(g \mid g)$ & 0.99 & 0.9 & 0.99 & $\mathbf{0 . 3 7}$ & $\mathbf{0 . 9 9 5}$ & $\mathbf{0 . 9 9 5}$ \\
\hline Target $g$ at 3 years & 0.4 & 0.4 & 0.25 & 0.05 & 0.75 & 0.35 \\
\hline \hline
\end{tabular}

$\underline{\text { Scenario 1: High initial grass cover, low grazing pressure, and } 3 \text { consecutive seasons of drought. }}$ Model starts with $15 \% T, 75 \% g$, and $10 \% b(=B+B B)$ fractional cover. The grazing intensity quantile is low $(=0.2)$ and the rainfall quantile is poor for 3 straight growing seasons (soil moisture availability and stress avoidances quantiles $=0.25$ ). Under these conditions, progressive loss of herbaceous cover was expected, decreasing to $40 \%$ after three seasonal cycles.

Figure C.1a: Sensitivity of 3-season grass cover outcomes to variation in free parameter, $\mathrm{p}_{\mathrm{sm}}$ $(b \mid g)$. Fixed parameter values did not result in any free parameter values that would yield the expected amount of 3-season grass cover.

Figure C.1b: Analysis with modified fixed parameter estimates, which did yield a value for the free parameter, $\mathrm{p}_{\mathrm{sm}}(b \mid g)=0.005$, that resulted in $40 \%$ grass cover after 3 seasons. 


\section{$<$ FIGURE C.1 $>$}

Figure C.1: Grass fractional cover over 3 seasons for each scenario (Scenario 1 was analyzed twice, panels a and b), with color spectra representing the range of free transition probability values from 0 (blue) to 1 (red). Stars indicate target expected fractional grass cover after 3 seasonal cycles.

Scenario 2: Low initial grass cover, low grazing intensity, and three seasons of good rains. Model starts with $15 \% \mathrm{~T}, 5 \% \mathrm{~g}$, and $80 \% \mathrm{~b}$ fractional cover. The grazing intensity quantile is low $(=0.2)$ and the rainfall quantile is good (soil moisture availability and stress avoidances quantiles $=0.75$ ) for 3 straight growing seasons. Under this scenario, the expectation was slow recovery of grass cover to reach target estimate of $25 \%$ after 3 seasonal cycles.

Figure C.1c: Analysis of 3-season grass cover outcomes in response to variation in free parameter, $\mathrm{p}_{\mathrm{sm}}(b \mid g)$. This yielded a value for the free parameter, $\mathrm{p}_{\mathrm{sm}}(b \mid g)=0.095$, that resulted in $25 \%$ grass cover after 3 seasons.

$\underline{\text { Scenario 3: Low initial grass cover, high grazing intensity, and three seasons of good rains }}$ Model starts with $15 \% \mathrm{~T}, 5 \% \mathrm{~g}$, and $80 \% \mathrm{~b}$ fractional cover. The grazing intensity quantile is high $(=0.8)$ and the rainfall quantile is good for 3 straight growing seasons (soil moisture 
availability and stress avoidances quantiles $=0.75$ ). Under these conditions, the high grazing intensity was expected to result in a decrease in grass fractional cover to $5 \%$ after three seasons.

Figure C.1d: Analysis of 3-season grass cover outcomes in response to variation in free parameter, $\mathrm{p}_{\mathrm{gi}}(g \mid g)$. This yielded a value for the free parameter, $\mathrm{p}_{\mathrm{gi}}(g \mid g)=0.37$, that resulted in $5 \%$ grass cover after 3 seasons.

Scenario 4: High initial grass cover, low grazing, and good rain

Model starts with $15 \% \mathrm{~T}, 75 \% \mathrm{~g}$, and $10 \% \mathrm{~b}$ fractional cover. The scenario is intended to reflect robust rangeland dynamics with good rain and only wildlife grazing $\left(\mathrm{Q}_{\mathrm{gi}}=0.2\right)$. Under these conditions, we expected a resilient, highly productive but still variable system; even in wildlife conservation areas after a series of favorable seasons, some bare patches tend to persist. This scenario was selected to constrain the model from unrealistic scenarios of full grass colonization. Thus, the expectation was maintenance of high cover $(\mathrm{g}=75 \%)$ after 3 growing seasons.

Figure C.1e: Analysis of 3-season grass cover outcomes in response to variation in free parameter, $\mathrm{p}_{\mathrm{gi}}(g \mid g)$. This yielded a value for the free parameter, $\mathrm{p}_{\mathrm{gi}}(g \mid g)=0.995$, that resulted in $75 \%$ grass cover after 3 seasons.

$\underline{\text { Scenario 5: Typical initial grass cover, moderate livestock grazing, and average rains }}$

Model starts with $15 \% T, 35 \% \mathrm{~g}$, and $50 \% \mathrm{~b}$ fractional cover. The scenario represents a livestock system that is not under great stress, and the expectation was that such a system would maintain its moderate productivity, with grass cover at $35 \%$ over 3 years. 
Figure C.1f: Analysis of 3-season grass cover outcomes in response to variation in free parameter, $\mathrm{p}_{\mathrm{gi}}(g \mid g)$. This yielded a value for the free parameter, $\mathrm{p}_{\mathrm{gi}}(g \mid g)=0.995$, that resulted in $35 \%$ grass cover after 3 seasons. 


\section{Appendix D: Summary table of model evaluation and validation, or "evaludation" elements employed.}

We utilize the format proposed by Angusiak et al. (2014) and Grimm et al. (2014) to document the six elements of model evaluation and validation identified in the modelling cycle. The definitions of the terms are outlined in Table D.1, followed by a summary of the procedures undertaken in this study for each element.

Table D.1: Summary of "evaludation" elements of model evaluation and verification, paraphrased from Angusiak et al (2014) and Grimm et al. (2014).

Element Description

1. Data evaluation Evaluation of the quality of data used to parameterize or calibrate the model.

2. Conceptual model Evaluation of the scientific principles underlying the model's design and the evaluation simplifying assumptions made in implementing them in the model.

3. Implementation Technical verification that the program code is error-free and performing the verification calculations, algorithms, and workflow as expected.

4. Model output Calibration of model parameters and verification that the model outputs are verification consistent with observations.

5. Model analysis Analysis of the sensitivity of model output to various parameters and interpretation of emergent behaviors

6. Model output Corroboration of model predictions with empirical data that was not used in corroboration calibrating or parameterizing the model. 


\section{Data evaluation}

Water balance model parameters were empirically derived from 2-year field measurements at the study site, or taken from published literature, as indicated in the footnotes of Table A.1. Exceptions were (a) soil matric potential at wilting point for annual grasses, which were estimated relative to perennial grasses to reflect observations that annuals appear to experience full stress before perennials at the field site; and (b) runoff coefficients for BB patches, which were assumed to have lower infiltration that B patches. (ref. section 2.2.2)

Grazing intensity quantiles were qualitative estimates that spanned a range of conditions observed at and around the study site, with discussion with local herders (ref. section 2.2.4).

Transition probabilities were in part calibrated from repeated measurements on permanent transects over 7 years. However, due to differences in the way vegetation was quantified in the model and in the field, relating the two required several transformations of available field data (see Appendix B). Since bare patches in the field were characterized by their surface hardness rather than age, we did not have strong data to relate to transition rates for $B$ vs. $B B$ patches.

\section{Conceptual model evaluation}

The hydrological submodel's simplifying assumptions draw from an extensive literature on ecohydrological dynamics in drylands. Previous publications on the hydrological submodel (Franz et al., 2010, 2012), an interesting body of work on Hortonian flow patterns (reviewed in 
Franz et al., 2012), and the consequences of different representations of root competition for water were considered in developing the model's approach.

The representation of grazing intensity was based on ecological foraging theory and the concept of ideal free distributions, which have been applied to grazing systems, where ungulates distribute their foraging effort in a frequency-dependent manner, according to the quality and quantity of resources. A particular advantage of this conceptual framing is that it also aligns with ethnographic findings related to herder decision-making. Herders tend assess the status of rangelands via the foraging efficiency of their animals, as manifest through weight gain or milk yields. (ref section 2.2.4)

\section{Implementation verification}

The hydrological model implementation was verified during its previous development (see Franz et al., 2012). We verified that the computer code for the hydrological submodel was still performing as expected in the full MVUACHACHE model, we tested to ensure that hillslopes and cells still achieved mass conservation at each timestep and season (ref. section 2.2.2).

The calculation of soil water availability and water stress avoidance quantiles entailed fitting a generalized extreme value (GEV) distribution to the seasonal average soil moisture parameters. The goodness of fit served to verify that the stochastic rainfall simulation algorithm was functioning as intended (ref. section 2.2.3). 
During the transition probability calibration, we noted that the model behaved as expected under a wide range of simulated conditions, which helped verify that the code was functioning properly (ref. Appendix C).

4. Model output verification

The hydrological model calibration was reported in Franz et al. (2012), and was largely based on empirical soil moisture traces at varying depths and runoff measurements, collected over a 2 year period at the study site.

The transition probability function calibration was a complex task, which also involved data evaluation and model analysis. To avoid over-calibration and excessive parameter tweaking, we calibrated the transition functions to generate expected behavior in a handful of 3-season endmember scenarios. Those expected behaviors were informed by observations, local and ecological expert opinion, and quantification of patch-level vegetation change on permanent transects over 7 years. The scenario-based calibration efficiently narrowed in on plausible transition probabilities without evaluating their effects on model behavior for longer than 3 seasons (ref. Appendix C).

5. Model analysis

Sensitivity analysis of the hydrological model's non-spatial components was reported in Franz et al. (2010), while Franz et al. (2012) analyzed hydrological submodel sensitivity to spatial 
processes of horizontal water redistribution and root competition for water ( $f r$ and $R C R$ parameters, respectively).

Model output sensitivity to grazing intensity was analyzed, and contextulized relative to the effects of $f r$ and $R C R$. We focused on fractional vegetation cover as the attribute of model output of greatest interest to this study (ref. section 2.3).

Model output sensitivity to bare patch (B and BB) transition probabilities was also conducted, since we had the most uncertainty regarding these variables, based on the weak transferability of empirical field data to the estimation of these parameters (ref. section 2.3).

Emergent spatial patterns in model output were analyzed. We found no evidence of regular pattern formation (such as banding or other regular shapes), but we did find that vegetation density increased markedly below the $100 \mathrm{~m}$ contour of the hillslope domain under some grazing conditions (ref. section 3.3).

6. Model output corroboration

To corroborate the emergent hillslope-scale vegetation dynamics, we used empirical vegetation data from which we could calculate seasonal shifts in hillslope-scale fractional vegetation cover (ref. section 2.4). 
a)

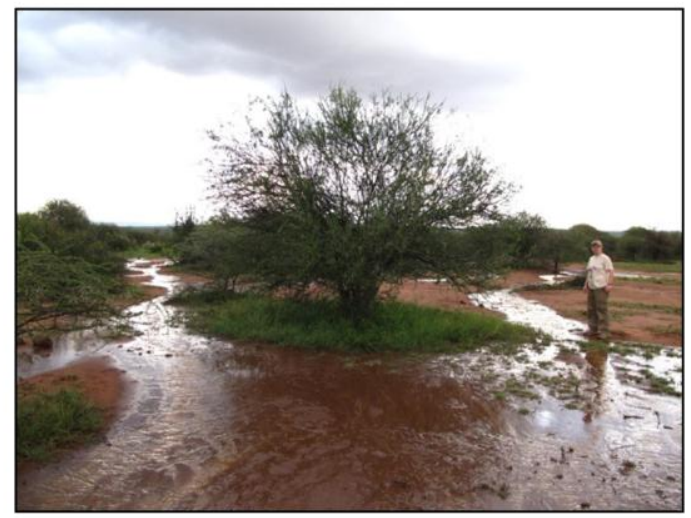

b)

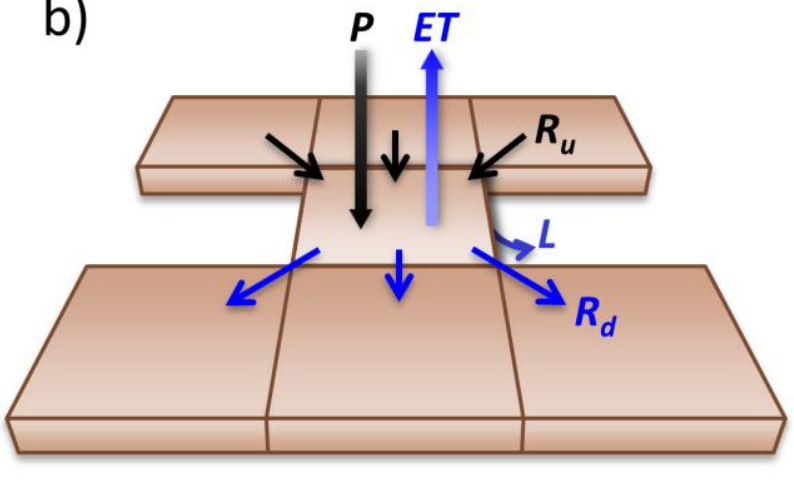

Figure 1. a) Photograph of typical patchy landscape and surface water redistribution following a rain event at the study site (courtesy of K. Caylor and F. O'Donnell, April 2010). b) Patch based water flux diagram of the ecohydrologic model developed by Franz et al. 2012. Following a rainfall event, the modeling computes runoff and runon from the 3 upslope $\left(R_{u}\right)$ and 3 downslope patches $\left(R_{d}\right)$, evapotranspiration $(E T)$, and leakage below the effective rooting zone $(L)$. The mean daily soil moisture for the 1 layer model is used to compute a vegetation water stress value. 


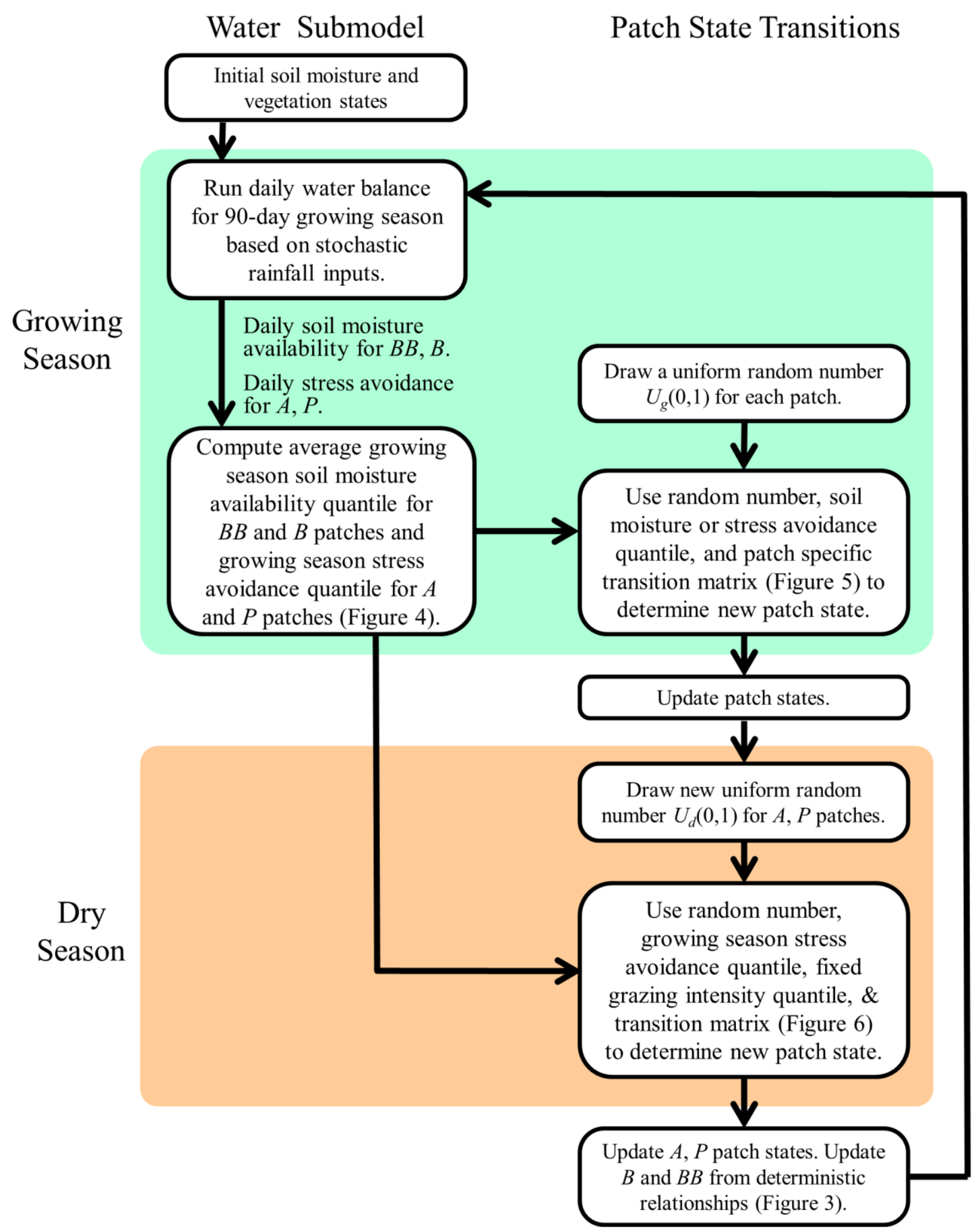

Figure 2. Framework and workflow of the water balance model and patch transitions through one growing season and one dry season. Patches can transition between 4 possible states: annual grass $(A)$, perennial grass $(P)$, bare soil $(B)$, or degraded bare soil $(B B)$. 


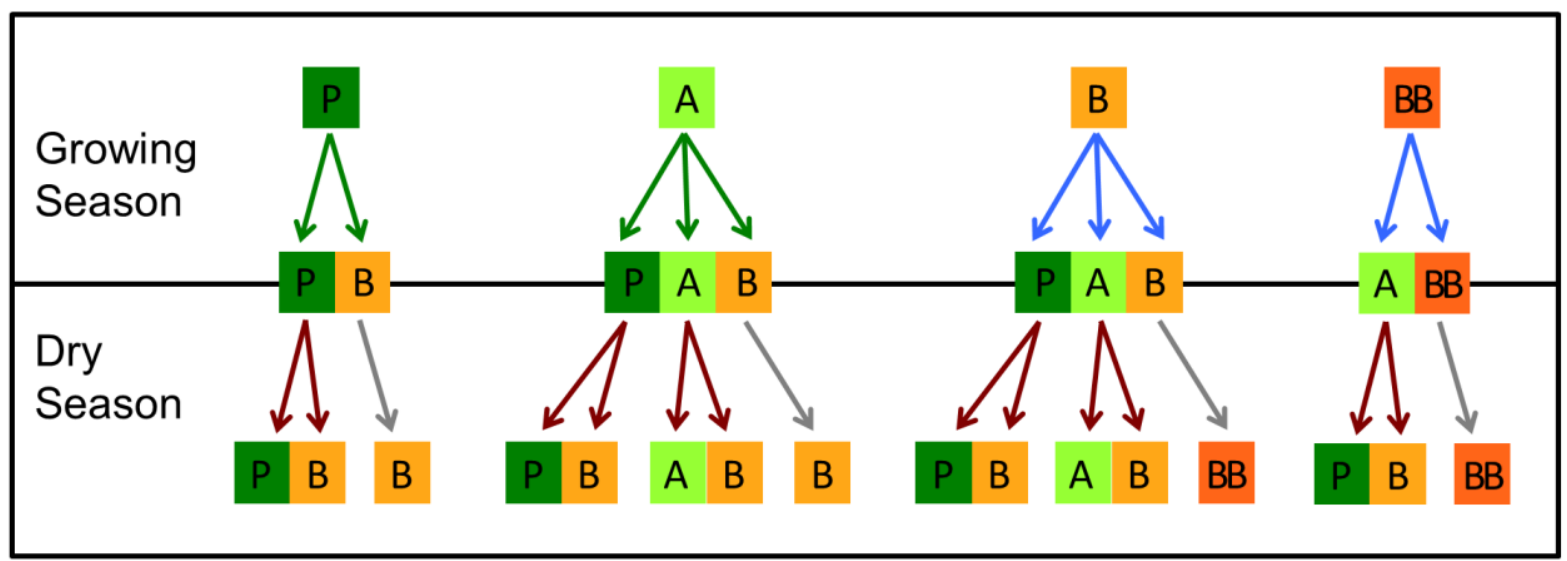

Figure 3. Patch state diagram illustrating the potential change in patch state during the growing season and during the dry season. Patches can transition between 4 possible states: annual grass $(A)$, perennial grass $(P)$, bare soil $(B)$, or degraded bare soil $(B B)$. Patch state transitions connected by blue arrows are based on growing season soil moisture availability quantile; patch states connected by green arrows are functions of plant stress avoidance quantile, patch states connected by brown arrows are based on grazing intensity quantile and the previous growing season plant stress avoidance. Patch states connected by gray arrows are determined by the duration of bare soil state: only patches that were bare $(B B$ or $B)$ at both the beginning and the end of the growing season, will be $B B$ at the end of the dry season. Tree patches ( $T$ ) remain fixed in time. 

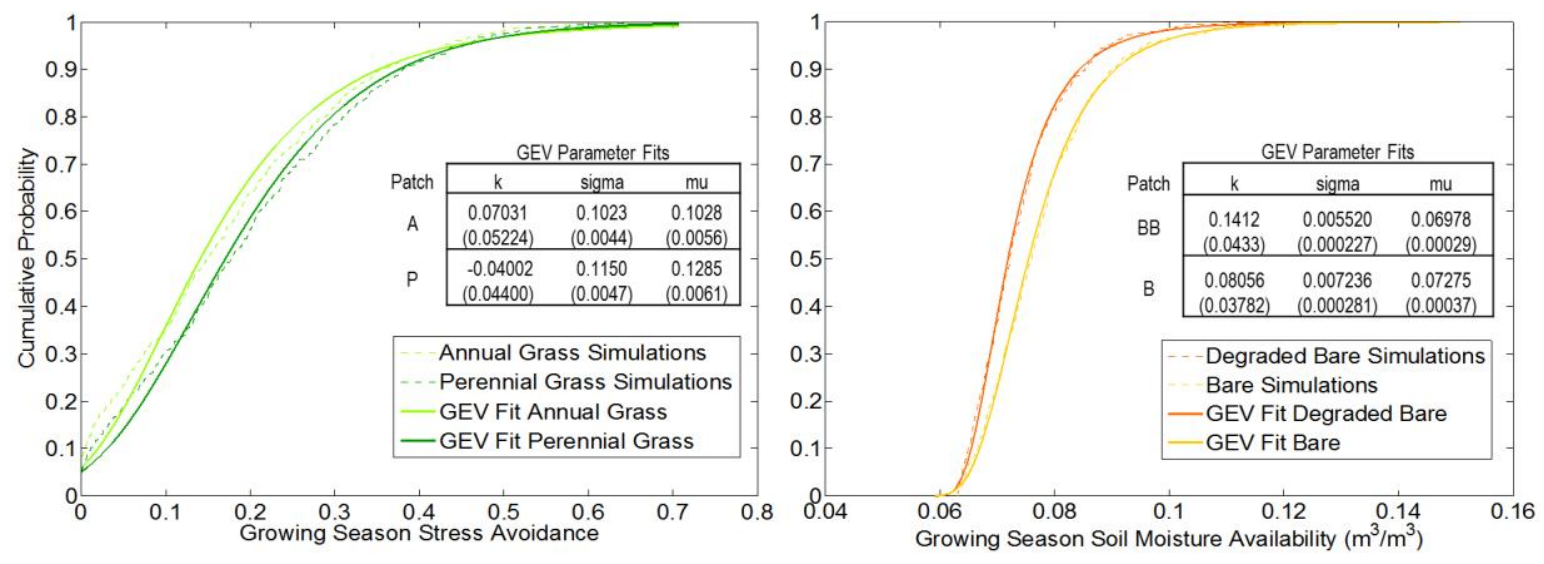

Figure 4. Curves show in solid lines the computed CDFs of daily average (a) water stress avoidance for $A$ and $P$ patches, and (b) soil moisture for $B$ and $B B$ patches, derived from simulations of 50090-day rainy seasons for each patch type. The dashed lines show 3-parameter generalized extreme value (GEV) fits to each CDF. Embedded in each figure are the GEV parameters for each patch type, which were used to compute soil moisture availability and stress avoidance quantiles. The transform of $\log _{10}(1+$ stress avoidance $)$ was used. Values in parentheses are standard errors of the parameter estimates from the 500 growing season simulations. 
a)

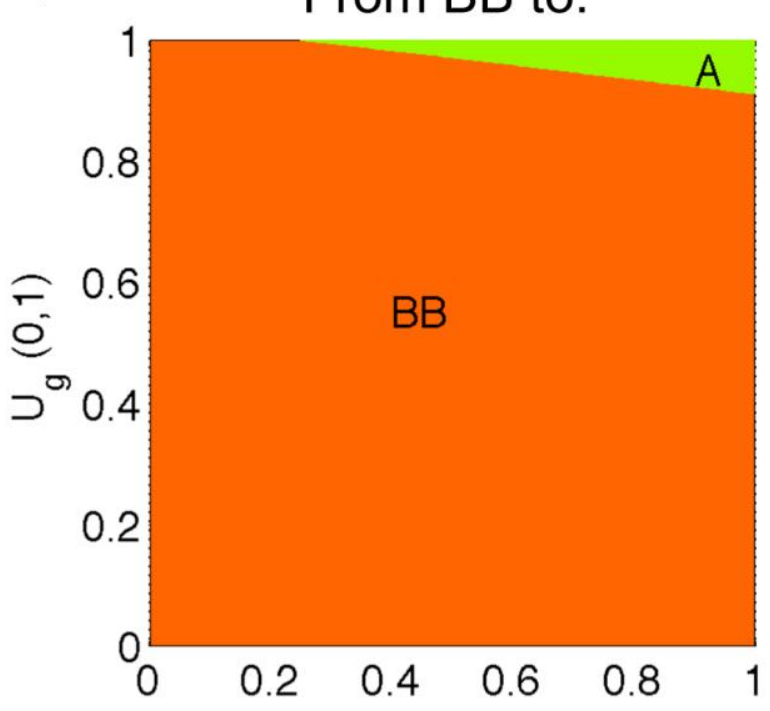

b)

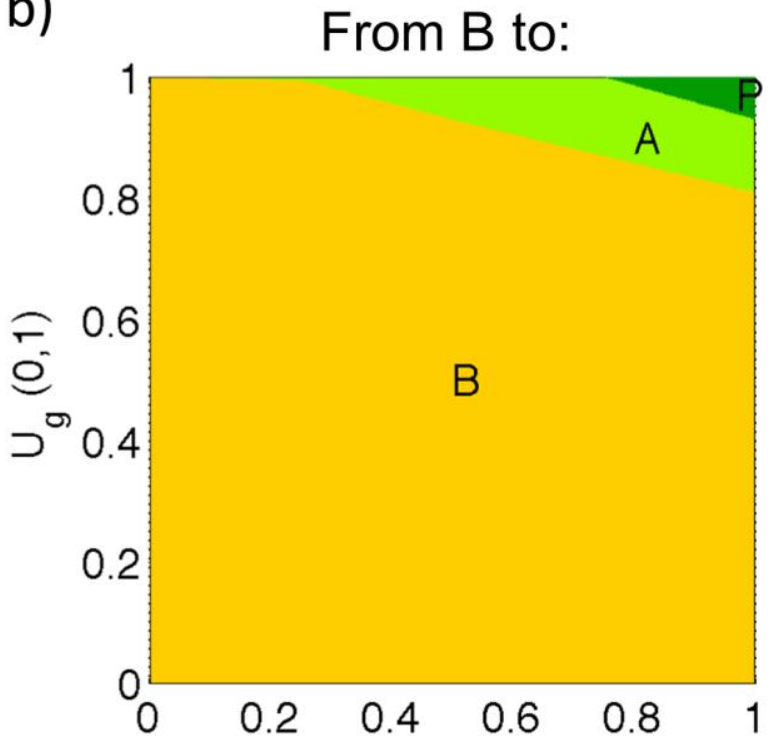

Soil Moisture Availability Quantile $\left(Q_{\mathrm{sm}}\right)$
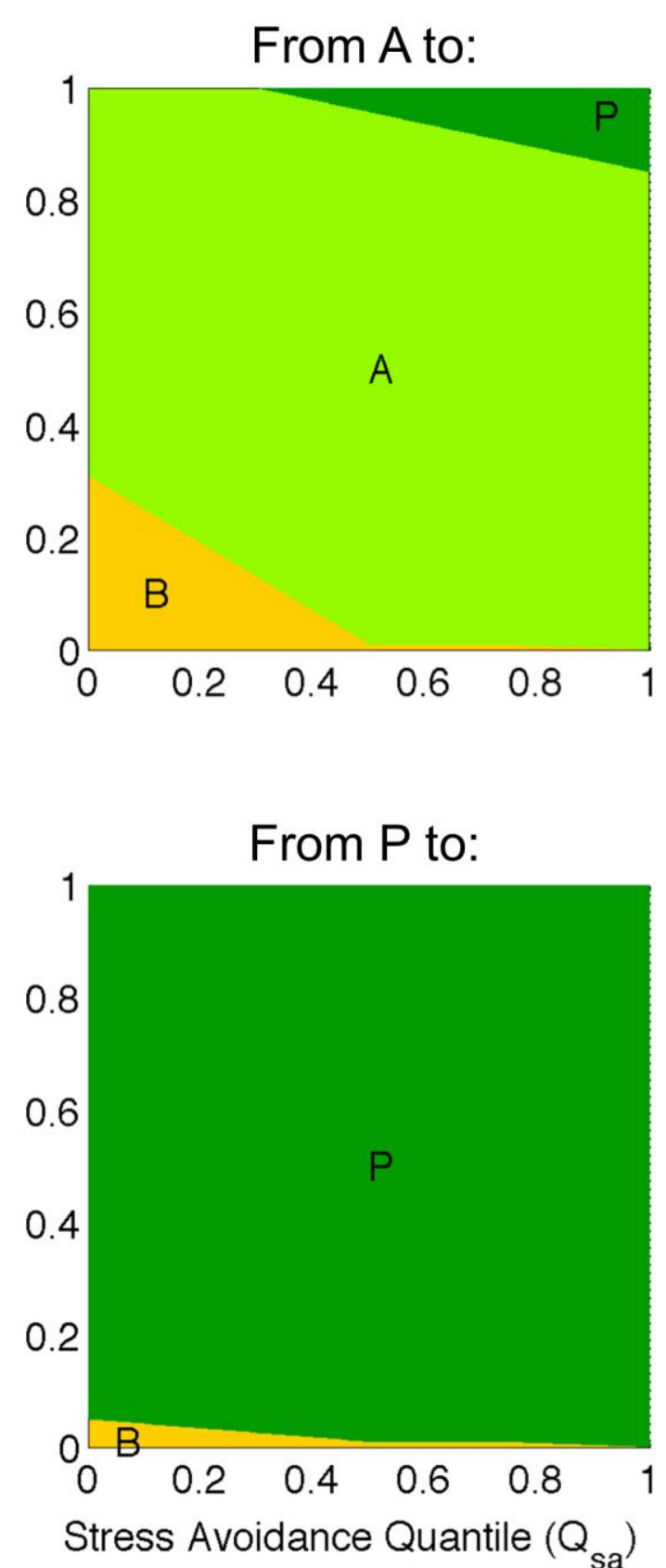

Figure 5. Growing season probability transition matrices based on the soil moisture availability quantile for $B B$ and $B$ patches, and the stress avoidance quantile for $A$ and $P$ patches (panels a, b, c, and d, respectively). The y-axis is the lookup value to which each cell's assigned growing-season uniform random number, $U_{g}$, is compared in order to determine the transition for each cell. 


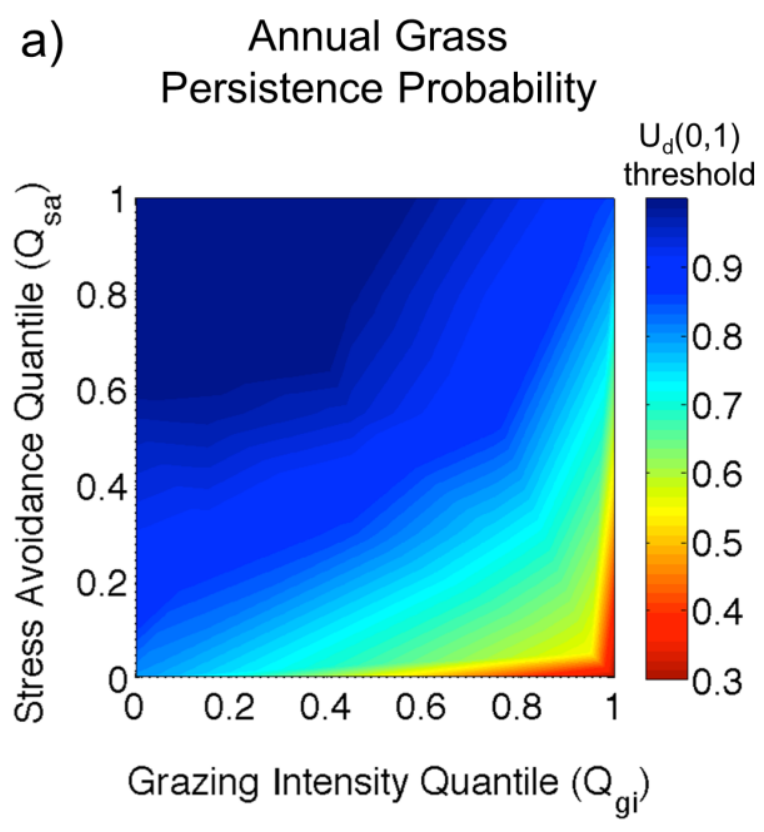

\section{Perennial Grass
Persistence Probability}

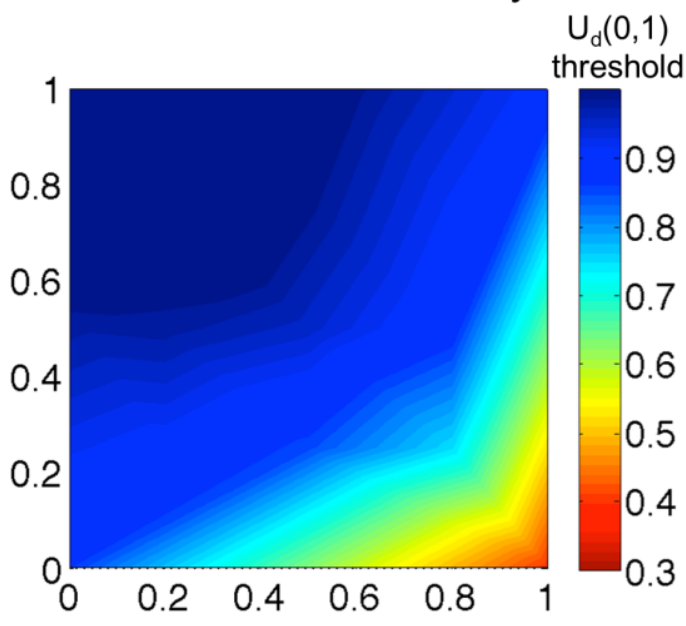

Grazing Intensity Quantile $\left(Q_{\text {gi }}\right)$

Figure 6. Derived transition probability thresholds based on grazing intensity quantile ( $\mathrm{x}$ axis) and previous growing season's stress avoidance quantile (y axis) for $A$ and $P$ patches (panels a and $\mathrm{b}$, respectively). The color index indicates probability of persisting as an $A$ or $P$ patch, and serves as a threshold lookup value, to which each cell's assigned dry-season uniform random number, $U_{d}$, is compared. If $U_{d} \leq$ threshold value, patch persists. If $U_{d}>$ threshold, patch transitions to $B$. $A$ patches are assumed to be more negatively impacted by dry conditions and grazing pressure than $P$. 


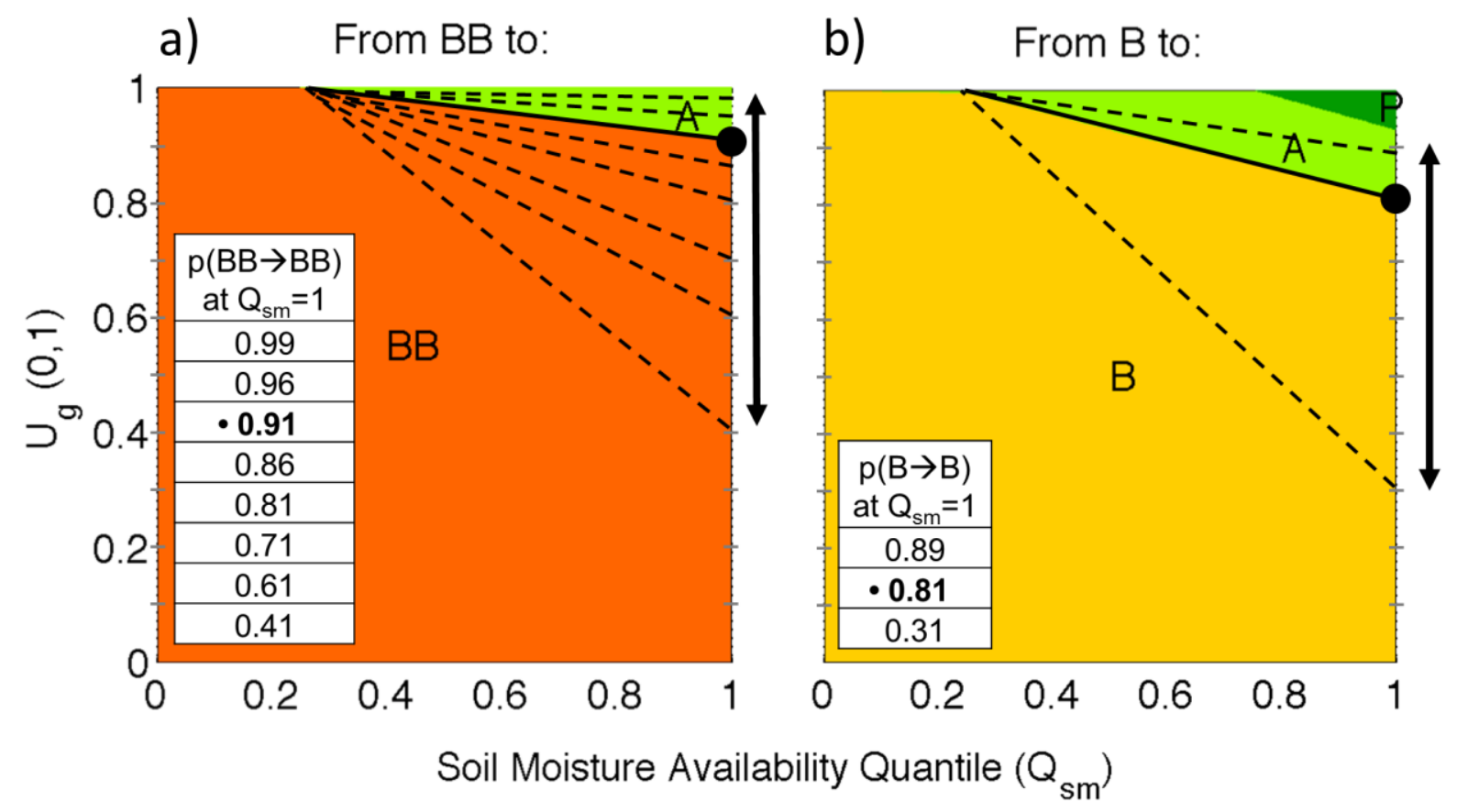

Figure 7. Range of growing season probability transition matrices for $B B$ and $B$ patches used in sensitivity analysis. a) Solid line indicates the $B B \mid B B$ transition function used throughout other simulation experiments, and dashed lines indicate 7 other functions derived by shifting the $\mathrm{p}(B B \mid B B)$ at $Q_{s m}=1$ (black dot) up and down in increments of 5 or $10 \%$. b) Solid line indicates the $B \mid B$ function used in other simulation experiments, black dashed lines indicate 2 other functions at which all $8 B B \mid B B$ variants were simulated. The $B$-to- $P$ rate was not altered. The values for each persistence probability at $Q_{s m}=1$ are embedded in each graph; the black dot indicates the value used in other simulation experiments. 
a)

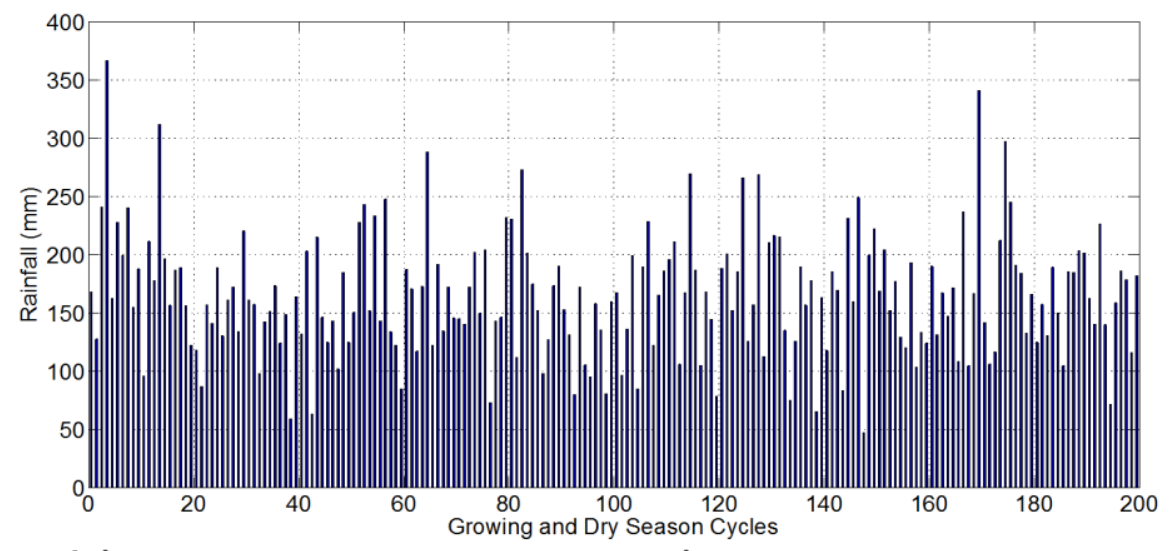

b)

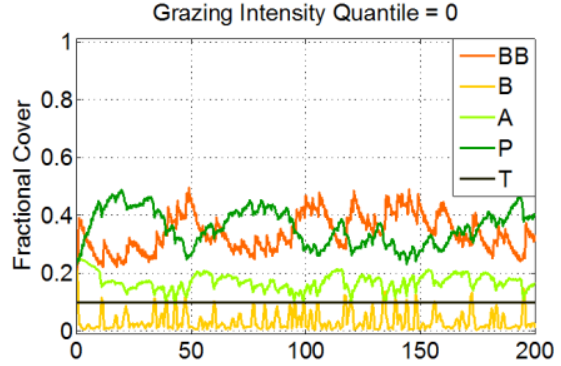

e)

c)
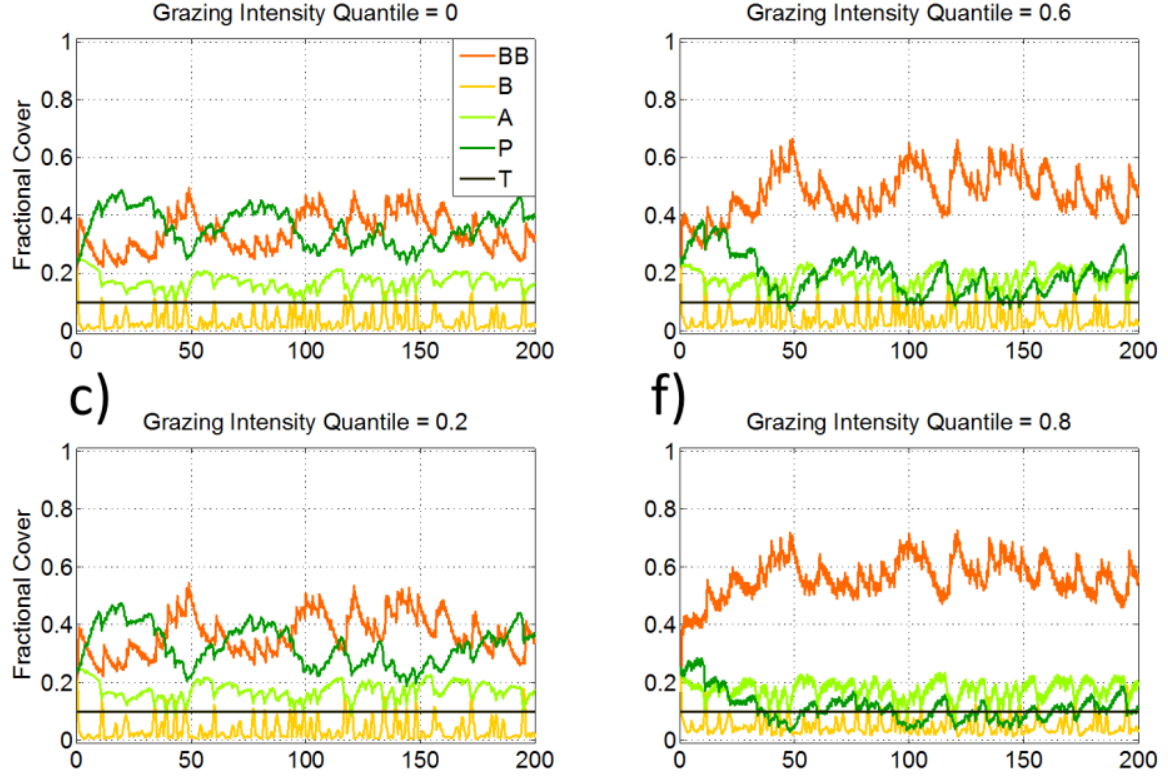

f) Grazing Intensity Quantile $=0.8$

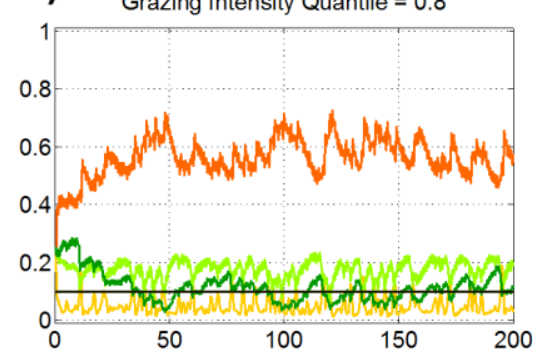

d) Grazing Intensity Quantile $=0.4$

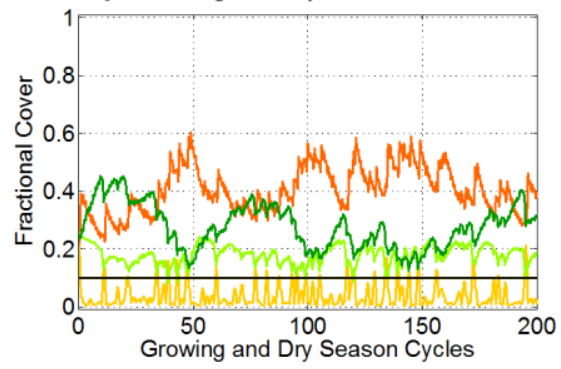

g) Grazing Intensity Quantile = 1

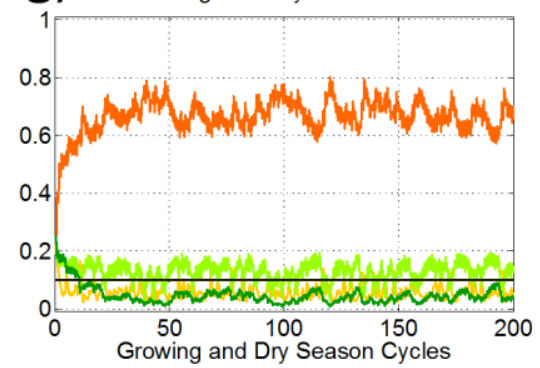

Figure 8. (a) Simulated growing season rainfall totals for 200 growing seasons using daily stochastic rainfall characteristics. (b-g) Time series of domain averaged fractional covers of $B B, B, A, P$, and $T$ for various grazing intensity quantiles. Note $R C R=3$ and $f r=0.1$ for all simulations, representing likely site conditions, and $T$ was set to $10 \%$. Animations of all simulations are available online as supplementary material. 

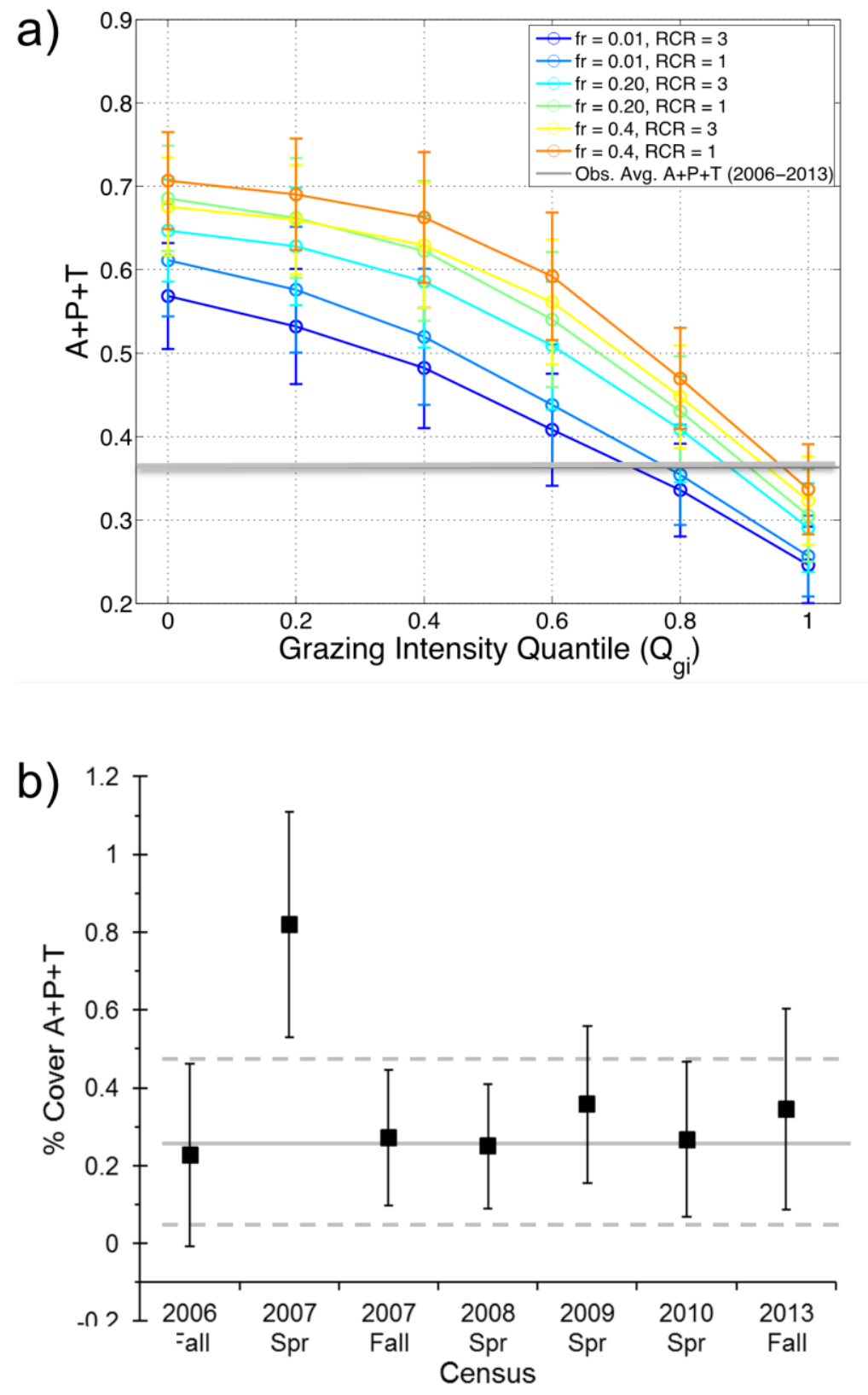

Figure 9. (a) Simulated $A+P+T$ fractional cover for different grazing intensities $\left(Q_{g i}\right), f r$, and $R C R$ values. Graphs illustrate the mean \pm 1 s.d. for growing-season and dry-season simulations (for seasons 25-200). The gray horizontal line at $36.3 \%$ is the mean fractional cover observed empirically at the study site, derived from data shown in (b).

(b) Observed vegetation $A+P+T$ fractional cover from 7 censuses of permanent transects at study site. In each census, the fractional cover on each transect was calculated, and the means \pm 1 s.d. are plotted. The solid and dashed gray lines in the background indicate the mean and s.d., respectively, of the census means. Based on measurements and model calibration, conditions at the study site are expected to correspond to $Q_{g i}$ between 0.6 to $0.8, f r=0.1$ to 0.2 , and $R C R=3$. 

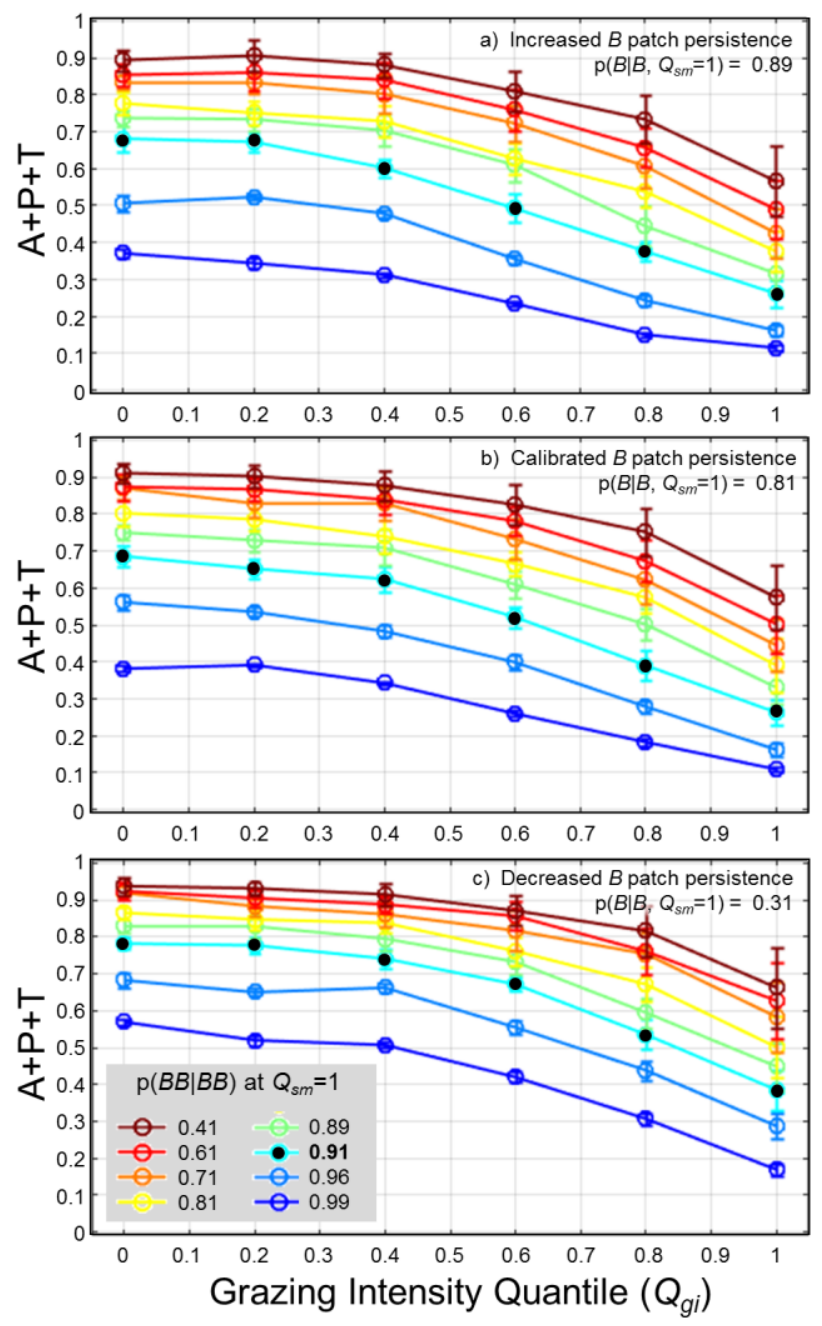

Figure 10. Sensitivity analysis of hillslope fractional vegetation cover $(A+P+T)$ to variation in growing season probability transition matrices for $B B$ and $B$ patches. Each panel shows incremental changes in growing season $B B$ persistence rates as different colored lines. Transition functions were modulated by varying $B B$ patch persistence probability, $\mathrm{p}(B B \mid B B)$, at the highest soil moisture quantile, $Q_{s m}=1$, and recalculating the transition function. Cyan lines with filled symbols represent the calibrated $B B$ transition function used in other simulation experiments described in this report. The three panels (a, $\mathrm{b}$, and c) represent the calibrated and two fairly extreme variations in $B$ patch transition functions, which were modulated in an analogous way to $B B$ functions. The three scenarios represent: a) increased $B$ patch persistence (lower recolonization), b) calibrated $B$ patch persistence/recolonization rates, and c) decreased $B$ patch persistence (higher recolonization). 
$Q_{g i}=0.2$

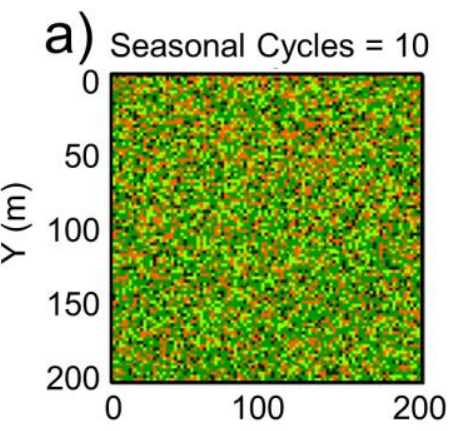

b) Seasonal Cycles $=20$

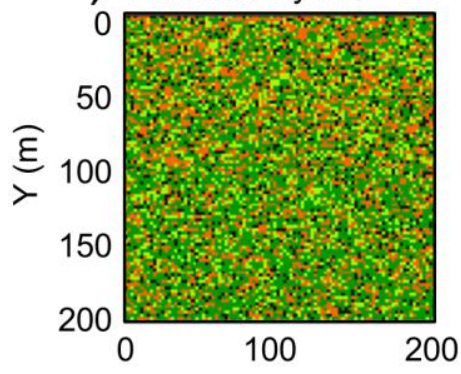

C) Seasonal Cycles $=30$

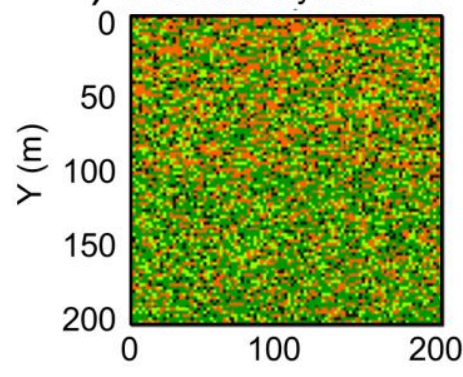

d) Seasonal Cycles $=40$

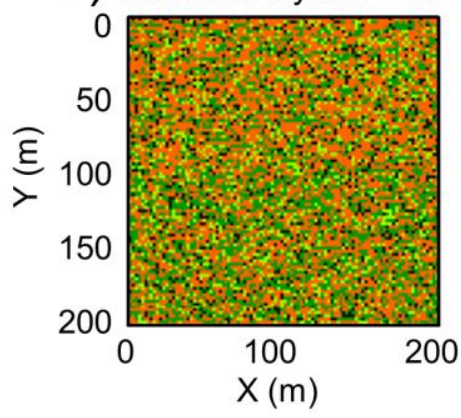

$Q_{\mathrm{gi}}=0.8$

e) Seasonal Cycles $=10$

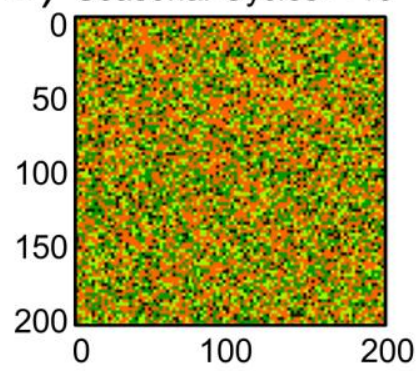

f) Seasonal Cycles $=20$

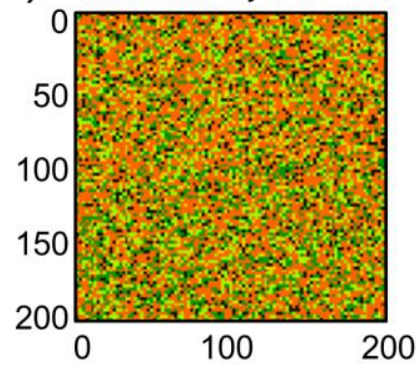

g) Seasonal Cycles $=30$

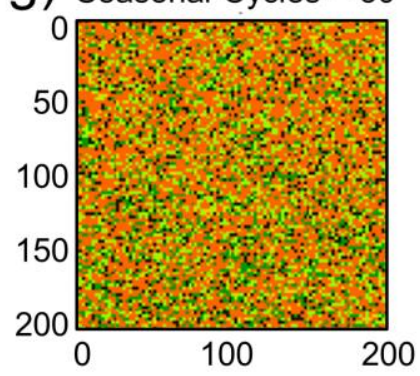

h) Seasonal Cycles $=40$

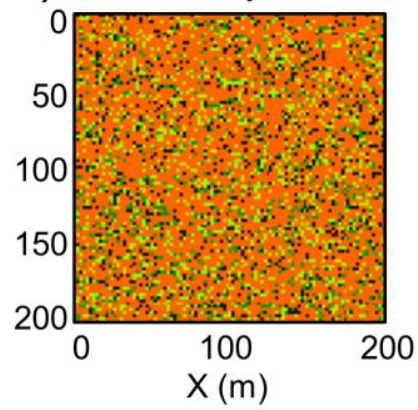

Figure 11. Spatial patterns of simulated $B B$ (dark orange), $B$ (light orange), $A$ (light green), $P$ (dark green), $T$ (black) for the first 40 seasonal cycles. The left column (a-d) is for grazing intensity quantile $\left(Q_{g i}\right)=0.2$ and the right column (e-h) is for a $Q_{g i}=0.8$. Note $R C R=3$ and $f r=0.1$ for all simulations, and $T$ was set to $10 \%$. Animations of all simulations are available online as supplementary material. 

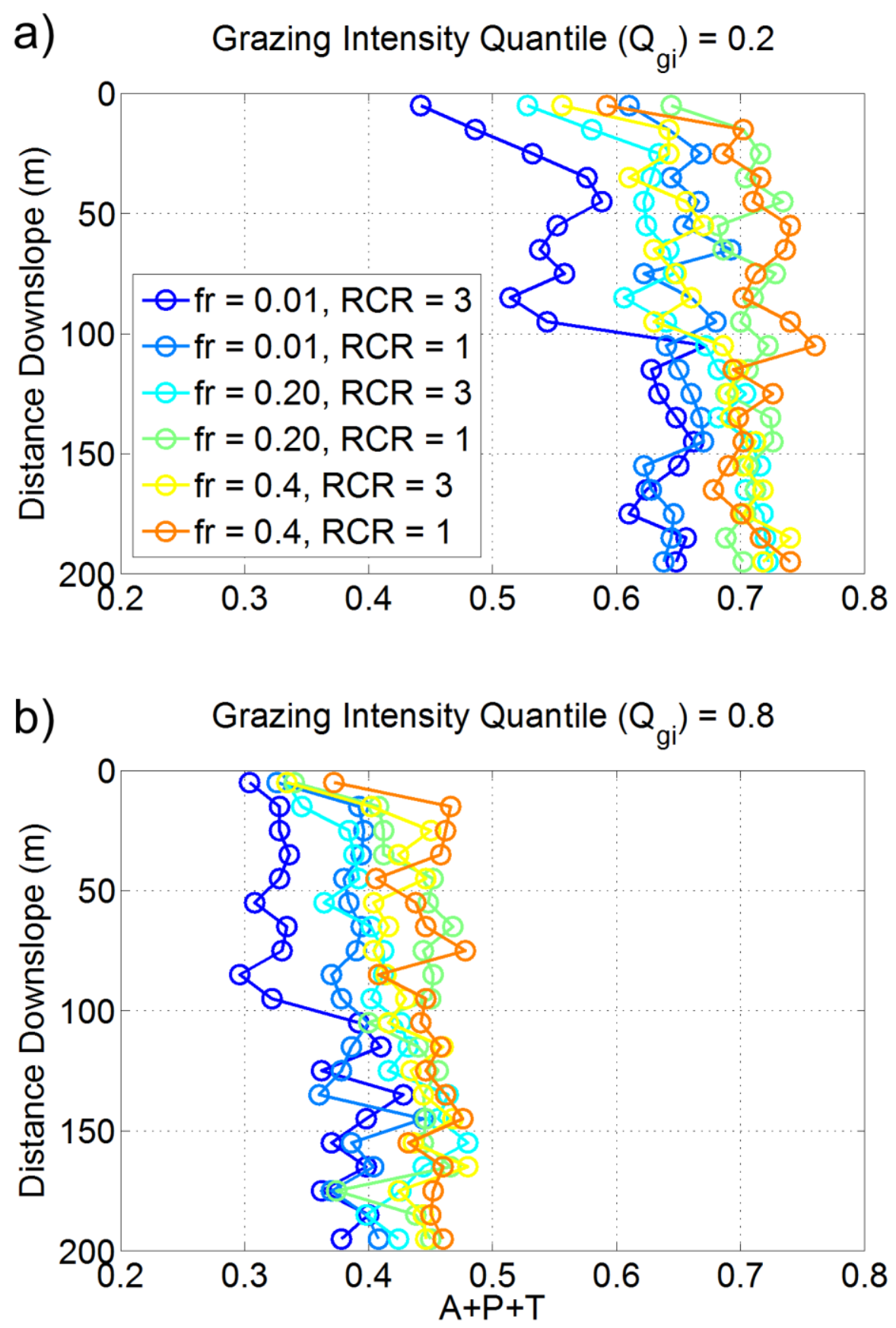

Figure 12. Average simulated $\mathrm{A}+\mathrm{P}+\mathrm{T}$ fractional cover ( $\mathrm{x}$ axis), calculated and plotted for each $10 \mathrm{~m}$ contour band on the hillslope domain (y axis), for different $f r$ and $R C R$ values. (a) Grazing intensity quantile $Q_{g i}=0.2$; (b) Grazing intensity quantile $Q_{g i}=0.8$. 


\section{a) Scenario 1a}

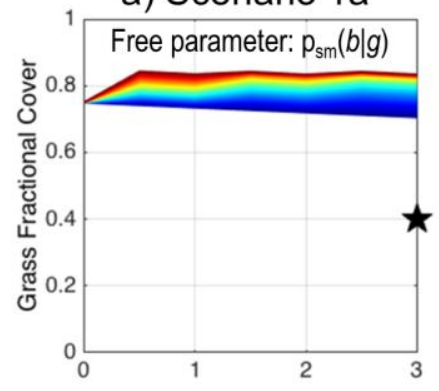

d) Scenario 3

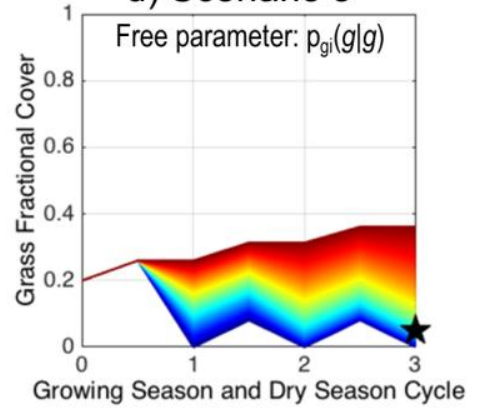

b) Scenario $1 \mathrm{~b}$

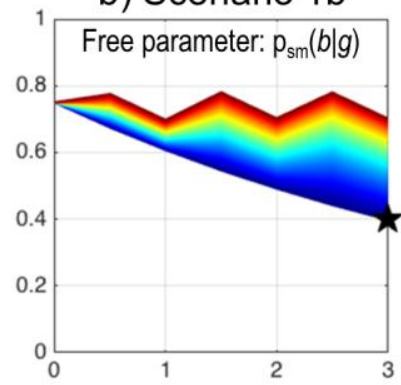

e) Scenario 4

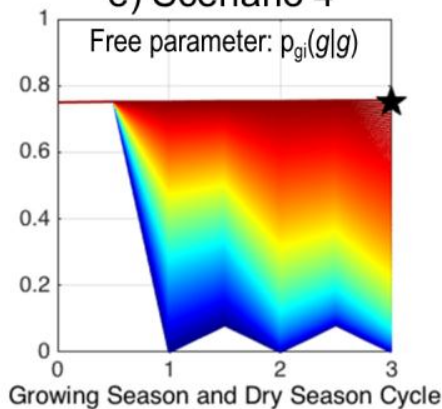

c) Scenario 2

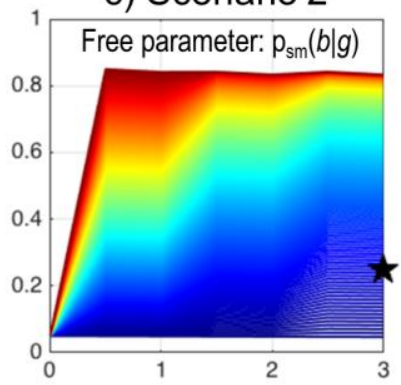

f) Scenario 5

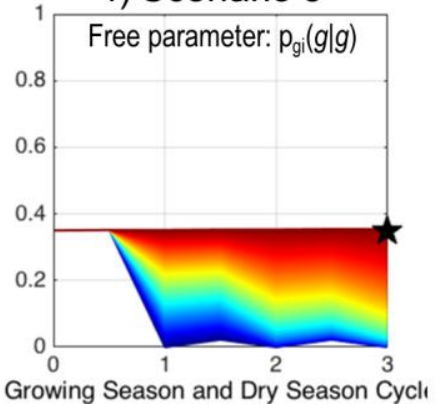

Figure C.1: Grass fractional cover over 3 seasons for each scenario (Scenario 1 was analyzed twice, panels $a$ and $b$ ), with color spectra representing the range of free transition probability values from 0 (blue) to 1 (red). Stars indicate target expected fractional grass cover after 3 seasonal cycles. 


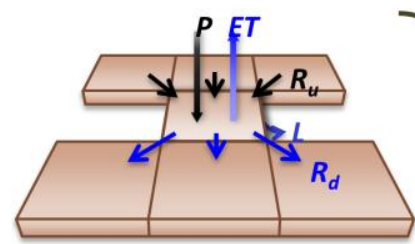

Ecohydrological Model

Perennial
Annual
Bare
Degraded

Patch Types
Probabilistic Transition Functions

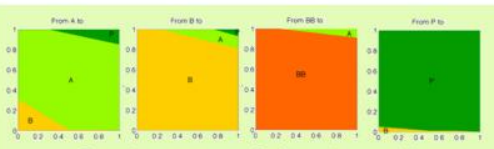

Growing season: Soil moisture-driven
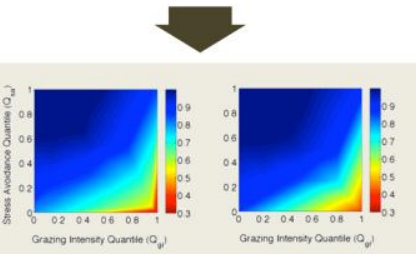

Dry season: moisture and grazing-driven
Hillslope Vegetation Dynamics

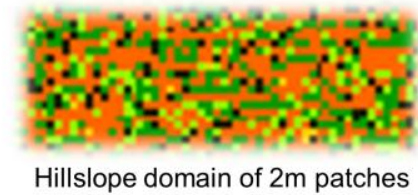

Hillslope domain of $2 \mathrm{~m}$ patches

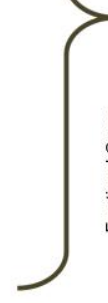

Temporal shifts in vegetation

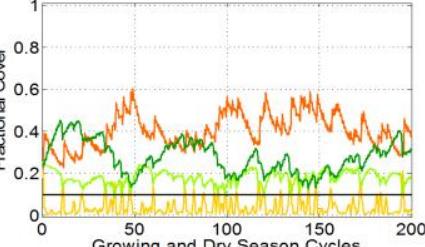

